\title{
Teorías de los fines de la pena: la problemática aplicación de la prevención especial en la política criminal peruana $a^{(*)\left(^{* *}\right)}$
}

\author{
Theories of punishment: the problematic application of the individual \\ prevention in the peruvian criminal policy
}

\author{
Fabrizio Gabriel Farfán Ramírez ${ }^{(* *)}$ \\ Universidad Peruana de Ciencias Aplicadas (Lima, Perú)
}

\begin{abstract}
Resumen: Debido al existente monopolio punitivo y penitenciario en el Perú, y en gran parte del mundo, los Estados deben justificar mediante una finalidad, el daño que la imposición de una pena causa en el individuo. Ante ello, la política criminal peruana opta por acoger una teoría ecléctica, cuyo mayor relieve se encuentra en la prevención especial. Sin embargo, pese a ser la prevención especial el núcleo de la teoría acogida, este precepto no se ve correctamente materializado.
\end{abstract}

El presente artículo desarrolla el fundamento y los problemas de las diversas teorías de los fines de la pena, las cuales se presentan como una opción de aplicación para el legislador peruano. Analiza, además, la estigmatización, la presión mediática y el exceso de privaciones de libertad. Problemas que impiden la materialización de la prevención especial en el Perú.

Palabras clave: Derecho Penal - Pena - Teorías de la pena - Fines de la pena Prevención - Retribución - Culpabilidad

\begin{abstract}
Due to the punitive and penitentiary monopoly in Peru, and in much of the world, States must justify, through a purpose, the damage that the imposition of a penalty causes in the individual. Given this, the Peruvian criminal policy chooses to embrace an eclectic theory, whose greatest importance is found in individual prevention. Nonetheless, despite individual prevention being the core of the accepted theory, this precept does not appear to be properly materialized.

This article develops the foundation and problems of the various theories of the punishment, which are presented as an application option for the Peruvian legislator. It also analyses stigmatization, media pressure and excessive deprivation of liberty. Problems that prevent the materialization of individual prevention in Peru.
\end{abstract}

Keywords: Criminal Law - Punishment - Theories of punishment - Purposes of the punishment - Prevention - Retribution - Culpability

${ }^{*}$ ) Nota del Editor: Este artículo fue recibido el 18 de febrero de 2021 y su publicación fue aprobada el 8 de junio de 2021.

${ }^{* *}$ El autor agradece enormemente los aportes y la colaboración de sus maestros José Luis Velarde y Guido Mendoza Fantinato.

$\left(^{* * *}\right)$ Alumno de tercer ciclo de pregrado de la Facultad de Derecho de la Universidad Peruana de Ciencias Aplicadas. Practicante en el área de White-Collar Crime \& Compliance en el estudio Miranda \& Amado. ORCID: https://orcid.org/0000-0001-6670-9598. Correo electrónico: fabriziofarfanr@gmail.com 


\section{Introducción}

El Derecho, la filosofía y la teología, han invertido gran parte de su desarrollo dogmático en la búsqueda de un discurso legitimador para la pena, el cual, les permita justificar el daño causado voluntariamente en contra del transgresor de la ley (ley positiva, ley natural o ley divina). Sin embargo, pese a los esfuerzos por distanciar los conceptos de pena y daño, ambos conceptos solo se fueron homogenizando, hasta llegar a ser sinónimos.

Frente a ello, y debido a que la estructura democrática moderna concentra la actividad punitiva en un solo ente, el cual es el Estado, se debe justificar, mediante una finalidad, el daño que este último puede hacerle a un ciudadano por medio de la pena. La legislación peruana, justifica este daño, acogiendo diversas teorías, es decir, adoptando una teoría ecléctica. Dicha teoría, se basa en la prevención del delito (prevención especial y prevención general) y en la retribución del daño, mediante una gran preponderancia de la prevención especial.

No obstante, a pesar de que la prevención especial es el elemento más importante en esta teoría, "(...) no se cumple en su integridad por carencia de recursos y por otras circunstancias" (Villavicencio, 2019, p. 72). Del mismo modo, la prevención especial, presenta diversos problemas que, gracias al desarrollo de las ciencias penales, fueron identificados. ¿Cuáles son los problemas que impiden la materialización de la prevención especial en el Perú? ¿Por qué el Perú acoge una teoría ecléctica y no otra?

El objetivo del presente artículo está en responder, mediante un desarrollo de los fundamentos y los problemas de las diversas teorías de los fines de la pena, que se presentan como una opción de aplicación para el legislador peruano, por qué se acoge una teoría ecléctica y no otra. Asimismo, se busca identificar los problemas que impiden la materialización de la prevención especial en la política criminal peruana.

La pena, es, sin lugar a dudas, el tema teórico con mayor repercusión en la práctica y, a su vez, es determinante para la composición de todo el Derecho penal y de la política criminal. Asimismo, la pena le da sentido al proceso penal, puesto que la totalidad de éste gira en torno a su imposición o denegación. Es por ello que, tal como sostiene Villavicencio (2019) "cualquier rol que señale el Estado para la pena, lo sostiene también para el Derecho Penal" (p. 45). Fruto de esta situación es la imperante necesidad de clarificar el rol que la pena asume, dentro del ordenamiento jurídico peruano.

El presente trabajo está formado por cinco partes: la primera se ocupa de la pena, donde su abordaje se realiza de una forma objetiva y generalizada; la segunda, se centra en las teorías de los fines de la pena, sus fundamentos y sus problemáticas. La tercera, analiza cuál de las teorías es aplicada en el Perú; la cuarta parte, identifica los problemas que impiden la materialización de la prevención especial y, la última parte, consta de reflexiones.

Debido a la densidad conceptual propia de este tema, el autor opta por la elaboración de esquemas introductorios para los diversos capítulos que comprende el presente artículo.

\section{La Pena}

Según Beccaria (2020), las penas son "motivos sensibles" (p. 51) que se imponen sobre infractores de la ley. Este autor los llama "motivos sensibles", puesto que impresionan los sentidos del individuo y contrarrestan, dentro de su mente, las pasiones que pueden oponerse al bien universal. Sin embargo, debido a la capacidad limitada del ser humano, las ciencias penales deben conformarse con que la pena, el derecho penal y el Derecho, en general, sean, tal como afirma Silva (2015), "convenciones más o menos estables y difundidas, sin mayores pretensiones" (p. 13). En un contexto y tiempo determinado, cada país es el encargado de establecer las penas mediante un consenso. Esta discusión puede presentarse en el Parlamento o, en el caso peruano, en el Congreso; y dicho acuerdo únicamente se ve limitado por otro consenso, el cual es el primigenio y el más básico para la conformación de toda sociedad, es decir, la Constitución. Esta relatividad motiva una continua e incluso interminable labor de las ciencias penales; puesto que, lo que era justo hace cincuenta años, hoy ya no lo es más; y lo que es justo hoy, en cincuenta años ya no lo será.

La pena es amoldada acorde al contexto de un determinado país, presentándose de forma diferente cuando un Estado encuentra la paz o vive la guerra; puesto que en esta última son más severas. Asimismo, estas obedecen a las costumbres y tradiciones imperantes en una determinada sociedad. Empero, la pena nunca deja de ser "(...) la reacción frente a la infracción de una norma" (Jakobs, 1991, p. 8), ni tampoco “(...) una intervención coercitiva del Estado y una carga para el condenado" (Roxin, 1994, p. 99). En este sentido, la pena siempre es un castigo, por más que algún individuo no sufra por su imposición o se vea beneficiado por ella, como el vagabundo que mejora su calidad de 
vida dentro de prisión. Pues, tal como afirmó Silva (2015), "se trata de una objetiva inflicción de daño o, en otros términos, de una restricción de derechos pretendida como tal (y no como efecto secundario de una pretensión diversa) para expresar la descalificación del autor" (p. 234). Sea cual sea la finalidad que se le quiera acuñar a la pena, no escapa de estas definiciones.

De esto surge la pregunta, ¿es la pena un derecho o un deber del soberano? La pena, sin lugar a dudas, es un deber del soberano, pero un derecho del ciudadano. Cabe aclarar que no es un derecho respecto a la figura de la venganza particular, imperante previa a la monopolización de la acción punitiva en el Perú(1) y en todo el mundo. Tampoco es un deber que responde a la figura de un Estado monárquico con el poderío de castigar a "diestra y siniestra". La pena representa un deber del soberano, en la medida de que, mediante ella, debe hacer que la libertad que cada individuo entrega, para la conformación de un Estado, tenga un sentido. Además, es un derecho del ciudadano, puesto que, cuando este no era un "ciudadano", tenía toda la posibilidad de realizar una venganza particular, pero, al ceder este poder al Estado, este tiene el deber de conseguir algún fin mediante la pena y, por su parte, el individuo el derecho de que este objetivo sea conseguido. De ello nace la necesidad de analizar cuáles son esos fines a los cuales puede aspirar un Estado por medio de la pena.

\section{Teorías de los fines de la pena}

A lo largo de la historia, la pena siempre estuvo presente junto al ser humano. Su presencia es ajena a la conformación de un Estado, manifestándose anteriormente a este, por medio de la venganza particular propia de la existencia de clanes y grupos familiares ${ }^{(2)}$. Sin embargo, al ser la pena indudablemente un pesar sobre quien esta cae, el Estado debe encontrar alguna justificación para su aplicación. Es ahí, donde entran las teorías de los fines de la pena. Estos planteamientos doctrinales, jurisprudenciales, legislativos y religiosos justifican la carga sobre un condenado.

Según Roxin (1976), "el derecho penal se enfrenta al individuo de tres maneras: amenazando con, imponiendo y ejecutando penas" (p. 20). Cada una de estas maneras describe los estadios en los que la pena, de acuerdo con las diversas teorías de los fines de la pena, actúa. Los preceptos absolutos ejercen en la imposición de las penas, las teorías relativas, intervienen en la amenaza (prevención general) o en la ejecución (prevención especial) y las teorías de la unión exhiben una mixtura entre estas dos. Finalmente, cabe precisar que, al momento de la imposición de la pena, las teorías absolutas miran al pasado, las teorías de la unión ojean el presente y las teorías relativas observan el futuro.

\subsection{Teorías absolutas}

Figura 1. Teorías absolutas

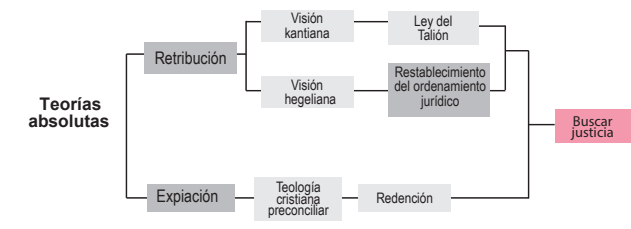

Fuente: Elaboración propia

Las teorías absolutas, o también llamadas teorías clásicas, se justifican en sí mismas sin aspirar a fines ulteriores como la intimidación - la corrección, lo que demuestra, según manifestó Maurach (1971), como se citó en Roxin (2017), "la majestad del Derecho desprendida de objetivos" (p. 77). El concepto "absoluto", según Roxin (1994), proviene del latín absolutus que traduce desvinculado. El significado de esta locución ya describe, en gran cuantía, el sentido de estas teorías, las cuales se encuentran totalmente ajenas a la consecución de alguna finalidad social, más allá de castigar un mal y lograr que el culpable tenga su merecido. Estas teorías limitan la función del Estado únicamente a la protección del individuo y parten del libre albedrío del ser humano.

Un sector de la más autorizada doctrina peruana opta por desligar la relación géneroespecie entre las teorías de los fines de la pena y las teorías absolutas ${ }^{(3)}$; de esta manera, agrupa las teorías absolutas dentro de las teorías penales. Lo anterior se lleva a cabo al sustentar la idea de que el término "fin" se entiende como utilidad social procedente de la

(1) En el caso peruano, el artículo 130.1 de la Constitución Política del Perú (1993) tipifica la unidad y exclusividad de la función jurisdiccional. Existen únicamente dos excepciones: en lo militar y en lo arbitral. En este mismo sentido, el Tribunal Constitucional en la sentencia STC 0006-2003-Al, afirmó que "(...) la función punitivo-jurisdiccional es privativa del Poder Judicial" (fundamento 18).

(2) Villavicencio (2019) difiere de esta concepción, pues según este autor el origen de la pena “(...) se encuentra vinculado con la del propio ordenamiento punitivo (...)" (p.45).

(3) En este sentido Meini (2013) 
imposición de la pena y que, por más que las teorías absolutas no rechazan la posibilidad de que la pena alcance otro fin, esto no interesa en su legitimación (Meini, 2013). Sin embargo, en palabras de Roxin (1994), las teorías absolutas, por una u otra vía, buscan la justicia. Tanto es así que, recientemente en su obra La teoría del delito en la discusión actual (2017), las llamó "teorías de la justicia" y aseveró que "no encuentra[n] sentido en ninguna utilidad, sino solo en la búsqueda de la justicia" (p. 80). Afirmación que es completamente correcta, dado que la pena en cada una de estas teorías obedece al concepto de justicia de sus partidarios.

Existen dos grandes doctrinas absolutas, la primera de ellas, es la doctrina de la Retribución, en la que se tienen como máximos exponentes a dos de los filósofos más importantes de la edad moderna: Immanuel Kant (1724-1804) y Friedrich Hegel (1770-1831). Aunque ambos coincidían en el postulado retributivo, estos filósofos tienen dos visiones completamente diferentes que surgen de la fundamentación moral y la fundamentación jurídica. La segunda doctrina absoluta es la de la Expiación, la cual se erige sobre la teología cristiana preconciliar. Cabe resaltar que Mir Puig (2016) no distingue entre la doctrina absoluta retributiva y la doctrina absoluta expiatoria, puesto que considera únicamente a la doctrina expiatoria una subclase de la doctrina retributiva.

En esta misma línea se encuentra Roxin (1976), quien no realizó distinción alguna, dado que para este autor la fe es la única forma de hacer plausible la idea de la compensación retributiva (borrar un daño mediante otro daño). Sin embargo, si se sigue la postura sostenida por Jescheck \& Weigend (1996), es necesario diferenciar entre la expiación y la retribución. El primer concepto alude a "un tributo moral propio del condenado que le conduce a aprobar la necesidad de la pena y a través del cual recupera su libertad moral" (p. 100). En contraste, la expiación se da en el fuero interno del individuo y tiene como requisito indispensable la disposición de este último por afrontar la pena y, de esta manera, recuperar su moralidad. Mientras que en la doctrina retribucionista, poco importa si el sujeto tiene o no voluntad por afrontar la pena, sino solo importa que la pena se le imponga.

Existen matices en común entre estas doctrinas. En primer lugar, que se configuran sobre el pensamiento de que el Estado es el encargado de hacer prevalecer la justicia terrenal. En segundo lugar, que parten del libre albedrío de la persona. Finalmente, ambas poseen el pensamiento de que el Estado debe limitarse al cuidado de la libertad individual (Jescheck \& Weigend, 1996). A continuación, se desglosan cada una de estas doctrinas.

\subsubsection{Retribución}

La primera de estas teorías absolutistas está dividida por dos visiones, la perspectiva sostenida por Immanuel Kant en su obra "La metafísica de las costumbres" (1785) y la visión de Friedrich Hegel en su obra "Líneas fundamentales de la Filosofía del Derecho" (1821).

La doctrina absoluta de la retribución, tal como Jescheck \& Weigend (1996) afirman, descansa sobre tres presupuestos:

a) Superioridad moral de la comunidad frente al delincuente.

b) Culpabilidad graduable a la gravedad.

c) Que el juicio se tenga por justo por el autor y la colectividad, debido a la armonía entre la culpabilidad y la pena.

Previo a profundizar estas dos visiones, es necesario recordar que la doctrina retribucionista aportó la concepción proporcional entre el delito y la pena $y$, por consiguiente, la limitación de la pretensión punitiva estatal (principio de culpabilidad). Asimismo, tanto Kant (1785) como Hegel (1821) comentaron que, buscar un fin resocializador o intimidatorio mediante la pena, es hacer que el hombre deje de ser hombre, es decir, que el ser humano pierda la esencia de tal. Para Kant (1785) el hacer esto ocasiona que el individuo sea tratado como un objeto del derecho de las cosas. Por su lado, Hegel (1821) manifestó que esto hace que el hombre sea tratado como un perro. No se puede olvidar que el principio sostenido, tanto por Kant (1785) como por Hegel (1821), fue años antes el núcleo de la filosofía de Cesare Beccaria (1738-1794). Este último es considerado el fundador del derecho penal moderno y en su obra De los delitos y la penas (1764) expresó la siguiente frase "no hay libertad cuando las leyes permiten que en algunas circunstancias el hombre deje de ser persona y se convierta en cosa" ( $p$. 185). Cabe destacar, que a diferencia de Kant (1785) y Hegel (1821), Beccaria (2020) no sigue el pensamiento retribucionista, debido a que, para Kant (1785) y Hegel (1821), la retribución es la única forma de honrar y dignificar al delincuente.

\section{A) Visión kantiana}

Para Kant (1785), el individuo "es un fin en sí mismo(4)" y la ley penal es un "imperativo categórico". Esto quiere decir, tal como

(4) Cabe aclarar que este valor asociado a la persona tiene como precursor a Cesare Beccaria en "De los delitos y las penas" (2020). 
desglosó Mir Puig (2016), "una exigencia incondicionada de la Justicia, libre de toda consideración utilitaria como la protección de la sociedad u otras" (p. 85), o, en otras palabras, "(...) un mandato de justicia libre de toda consideración final" (Jescheck \& Weigend, 1996, p. 104). Según Kant (1785):

Aun cuando se disolviera la sociedad civil con el consentimiento de todos sus miembros (por ejemplo, decidiera disgregarse y diseminarse por todo el mundo el pueblo que vive en una isla), antes tendría que ser ejecutado hasta el último asesino que se encuentre en la cárcel, para que cada cual reciba lo que merecen sus actos y el homicidio no recaiga sobre el pueblo que no ha exigido este castigo: porque puede considerársele como cómplice de esta violación pública de la justicia (pp. 168-169).

Este famoso ejemplo utilizado por Kant (1785) para describir su posición respecto a la pena, permite destacar tres puntos muy importantes. El primero de ellos, radica en que la pena debe ser impuesta, aun cuando sea completamente innecesaria para el bien de la sociedad; tanto es así, que el delincuente debe ser castigado incluso cuando la sociedad y el Estado dejan de existir. En contraposición a este precepto, Montesquieu (1748) señaló que es tiránica toda pena que no derive de una absoluta necesidad. Por ello, en la visión kantiana la pena no juega ningún papel preventivo general o preventivo especial.

Por el contrario, para Kant (1785), la persona debe ser castigada por el mal uso de su libertad. El segundo de estos puntos importantes a destacar, se fundamenta en que, para Kant (1785), si la sociedad omite castigar al delincuente el crimen recae sobre ella. Kant (1785), como se citó en Roxin (1996), afirmó que comete una calamidad quien por un propósito mundano cualquiera absuelve a un malhechor. Finalmente, Kant (1785) utiliza la Ley del Talión ("ojo por ojo diente por diente") como herramienta para llegar a la justicia. El ejemplo de la isla fue duramente criticado tanto por Klug (1970) ${ }^{(5)}$ como por Jakobs (1991). En primer lugar, Klug (1970), como se citó en Duran (2011), concluyó que el ejemplo de Kant es contradictorio, en la medida de ¿a quién debe responder la "deuda de sangre", si tal como lo narra Kant ya no existirá pueblo alguno? Asimismo, Jakobs (1991) ratificó la idea de que, en el ejemplo, Kant (1785) se refiere a la renuncia de una sociedad concreta y no a toda forma de sociedad; de ahí que Jakobs (1991) afirmó que "(...) la norma que tras la disolución de la sociedad siguiera siendo necesaria debería seguir siendo estabilizada" (p. 22).
Entonces, ¿esta teoría deja la puerta abierta para sumergirnos en un mundo lleno de venganzas privadas? La respuesta es negativa ${ }^{(6)}$. Esto pudo ocurrir anteriormente con la existencia de clanes y la venganza particular. Sin embargo, con la constitución de un Estado, la ley del talión pasa a manos de la administración estatal. Tan grande es la diferencia que, según Jakobs (1991), "[la ley del talión] limita la venganza a la medida de la pérdida del bien ocasionada por el hecho" ( $p$. 21). Con este mismo pensamiento, Jescheck \& Weigend (1996) también consideraron que "(...) la retribución nada tiene que ver con la venganza, con bajos sentimientos de odio o con caprichosas agresiones represivas de la sociedad, sino que es un principio de medida (Maßprinzip)"(7) (p. 99). Por esta razón, la ley del talión, más que representar un peligro para la sociedad, funciona como un principio de medida y es el valor retributivo más conocido. Lo anterior, únicamente cuando está en manos neutrales.

El problema radica en que con el pasar de los años se han incorporado tipos penales cada vez más complejos (v. g. delitos del derecho penal económico), en los que la aplicación de la ley del talión sería muy complicada e incluso imposible. Por ejemplo, en la actualidad, ¿cómo se podría justificar que el tipo especial de feminicidio tiene una pena, incluso mayor, que la del homicidio calificado? Si se usara estrictamente la ley del talión no podrían existir estos tipos especiales $\mathrm{y}$, es más, todos los homicidios deberían ser castigados con pena de muerte. Sin embargo, el legislador peruano, rechaza el uso estricto de esta ley y de la visión kantiana en general. Por ello, si recurrimos al Código Penal (1991), nos damos cuenta de que la búsqueda de fines sociales en el Perú se realiza incluso mediante tipos penales ${ }^{(8))}$.

(5) Ulrich Klug (1970) es el mayor detractor de la doctrina retribucionista, tanto así que, estas críticas llevaron el nombre de "Despedida de Kant y Hegel" (Abschied von Kant und Hegel). Asimismo, él ha formulado las críticas definitivas al pensamiento retribucionista, en el que afirmó excesos de un pensamiento lírico de dudosos fundamentos.

(6) Es necesario mencionar que otros autores enunciaron que esta visión motiva la "racionalización de la venganza". No obstante, lejos ya de un estado de guerra, la tesis jakobsiana tiene más sentido.

(7) La cursiva es de Jescheck \& Weigend (1996).

(8) Un claro ejemplo de esta situación, como ya se mencionó, es el tipo penal de feminicidio. Dicho tipo regulado por el articulo 108-B del Código Penal (1991) refleja el intento por parte del legislador de disminuir la cantidad de homicidios dolosos contra mujeres. 


\section{B) Visión hegeliana}

Hegel (1821) fundamentó su visión sobre el principio dialéctico ${ }^{(9)}$, en el que plasmó la voluntad general en el ordenamiento jurídico. Por ello, si cualquier sujeto, al hacer uso de su voluntad individual, niega el ordenamiento jurídico, es decir, comete así un delito, vulnera a su vez la voluntad general. Es así que la pena aparece como una negación de la negación que restablece el ordenamiento jurídico y, con ello, la voluntad general. La pena, tras la negación, consigue la anulación del delito, debido a la "superioridad moral de la comunidad" (Jescheck \& Weigend, 1996, p. 104).

Kant (1785) retribuyó la pena de acuerdo con el mal causado al otro individuo (si mata, tiene que morir). Sin embargo, para Hegel (1821), esto se mide de acuerdo con el daño causado a la voluntad general, lo que ocasiona que quede obsoleta para él la ley del talión. Pues, perfectamente, pueden existir delitos con una pena desproporcionada al daño individual causado, debido al daño que causó en el ordenamiento jurídico. Incluso, puede ser castigada con pena de muerte la sustracción de una fruta. Por esta razón, Wessels, Beulke \& Satzger (2018) afirman que, para restablecer la justicia, la pena debe ser similar en duración y en gravedad al injusto, "(...) según Kant, también en cuanto a la clase, mientras que, según Hegel, solo en cuanto al valor" (p. 10) ${ }^{(10)}$.

En esta misma línea, Jakobs (1991) expresó que “(...) en Hegel la pena es absoluta en lo conceptual, pero su concreta configuración es relativa al respectivo estado de la sociedad" ( $p$. $23)^{(11)}$. Esto quiere decir que para Hegel (1821), en sociedades más consolidadas, la pena puede ser menor, puesto que la peligrosidad del delito es más reducida, mientras que, en sociedades precarias y no consolidadas, la pena puede ser mayor, por la alta peligrosidad del delito contra la sociedad. Algo que debe ser resaltado, respecto a la visión hegeliana, es que algunos autores le atribuyen ser la base de la sistematización de la teoría del delito.

\section{C) Problemas de la retribución}

(i) El libre albedrío es indemostrable

La doctrina retribucionista asocia el delito con un mal uso de la libertad por parte del individuo. Por lo mismo, como ya se mencionó, la doctrina retribucionista parte del libre albedrío del ser humano, postulado que es completamente indemostrable de una forma empírica. De igual manera, estos autores plantearon el problema de la pena desde un plano absoluto e inmutable, lo que deja de lado el contexto social donde se desarrolla el delito. En otros términos, no se consideran los factores económicos, sociales y culturales que condicionan "la libertad absoluta". Del mismo modo, la acentuación pequeña, pero cada vez mayor de la neurociencia llevada a cabo por Taruffo y Nieva (2013) demuestra lo insostenible del "libre albedrío" y el gran avance de las ciencias penales por desmitificarlo.

\section{(ii) Racionalización de la venganza}

Claramente, la opinión sostenida por Jakobs (1991) y Jescheck \& Weigend (1996), por la que el presente autor se inclina ya con anterioridad $^{(12)}$, tiene objeciones, incluso, de parte del mismo Roxin (1976). Quien aseguró que es racionalmente insostenible que, al añadirse un segundo mal, se pueda borrar un mal anterior; postulado que solamente puede ser plausible mediante un acto de fe, el cual no se le puede imponer obligatoriamente a nadie. En otras palabras, no se puede recuperar la visión del ojo por más que se tengan en mano los ojos de todas las personas que causaron su pérdida.

(iii) El cuándo de la pena

Tanto Kant (1785) como Hegel (1821) dejaron al aire la respuesta de la pregunta ¿bajo qué presupuestos la culpabilidad autoriza

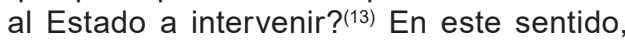
Roxin (1976) afirmó que uno de los mayores problemas de esta doctrina es el cuándo de la pena. Se presupone desde un inicio la

(9) Un gran resumen de las etapas de la filosofía hegeliana (tesis, antítesis y síntesis) es brindado por Custodio (2016), quien afirmó que "la tesis es entendida como el momento inicial y corresponde al estar en sí, es también la revelación del momento abstracto que será accesible al entendimiento. La antítesis comprende entonces el momento en el que el estar en sí, sale de sí mismo y se niega, logrando así objetivar el momento, llevando en si un plano "exterior" a sí mismo. Y por último se llega a la síntesis, que es entendida como una negación de la negación o una reconciliación con el momento inicial” (párrafo 15).

(10) La cursiva es de Wessels, Beulke y Satzger (2018).

(11) La cursiva es de Jakobs (1991).

(12) Véase la página 8.

(13) Cabe destacar que, a diferencia de los partidarios absolutistas, Beccaria (2020) sí manifiesta un cuándo y cómo de las penas. El autor desarrolló una escala que tiene, en primer grado, la destrucción inmediata de la sociedad y, en último grado, la mínima injusticia hecha a sus miembros individuales. La pena debe ser aplicada cuando el delito se encuentre dentro de estos parámetros, si no es así, la acción no puede ser tildada como "delito" y, mucho menos, puede ser castigada como tal. 
necesidad de la pena, pero no existen los presupuestos para la determinación de una acción que merece su aplicación. Si se debe retribuir la culpabilidad, ¿se debe retribuir toda culpabilidad?, es decir, ¿se debe castigar, incluso, la culpabilidad ínfima de la vida diaria? Estas respuestas quedan completamente difusas en esta doctrina, en la medida de que una persona puede realizar una acción culposa de muchas maneras $^{(14)}$.

Actualmente, la solución a este problema se consigue por medio de principios (principio de mínima intervención del derecho penal, principio de subsidiariedad y principio de mínima lesividad), como también, por medio del propio análisis de la teoría del delito (imputación objetiva).

(iv) Inaplicabilidad del in dubio pro reo

Tanto Kant (1785) como Hegel (1821) no consideraron los cambios que pueden ocurrir dentro del pensar de una comunidad y, consecuentemente, en la percepción de la sociedad sobre una determinada acción. De ello surge la siguiente pregunta: ¿se debería castigar al individuo, incluso, si el delito dejó de ser delito? Sin duda, el Derecho moderno responde con un rotundo no. Sin embargo, se debe precisar que los retribucionistas plantean sus postulados desde un plano absoluto e inmutable, lo que conlleva que su respuesta sea afirmativa.

\section{(v) No permite la racionalización de la reacción penal}

De utilizarse la doctrina retribucionista (sea la visión kantiana o hegeliana) la norma pierde su sentido. En esta línea, según Meini (2013) "la retribución per se no está en condiciones de legitimar la pena en un Estado que pretende racionalizar la reacción penal"(15) (p. 147). En correspondencia con esto, tal como sostuvo este mismo autor, si la pena adopta la visión kantiana (relación culpabilidad-pena) esta desatiende la necesidad social que constituye la razón de ser de la norma. Si, por otro lado, adopta la visión hegeliana (relación restablecimiento del ordenamiento jurídico-pena) el comportamiento que infringe la regla dejaría de ser el presupuesto de esta.

(vi) Inaplicabilidad de beneficios penitenciarios

La doctrina retribucionista no permite la aplicación de beneficios penitenciarios en los condenados. Los beneficios de libertad anticipada o los de mejora en la calidad de vida quedarían obsoletos, todos los ítems del artículo 42 del Código de Ejecución Penal (1991) serían inutilizables e, incluso, también la figura del indulto y de la amnistía.

La retribución del delito debe realizarse sin importar el comportamiento, la salud (mental o física) o las características del condenado. Lo anterior, debido a que, si se lleva a cabo algún beneficio, el valor de justicia se vería afectado. Esto conlleva a que los condenados sean esclavos de sus hechos, sin la más mínima esperanza de que un cambio positivo en su comportamiento modifique algo en su realidad. Por el contrario, ellos deben cumplir hasta el más mínimo daño retribuido.

(vii) Gran poder al legislador

Debido a que no existe un cuándo de la pena, la codificación está abierta a poder obedecer comportamientos arbitrarios y tiránicos por parte del legislador. Según Roxin (1976), si se dan los criterios de imputación, nada impide que cualquier conducta pueda ser castigada. De este modo, existe la posibilidad de que la codificación pueda ser usada como un instrumento de opresión por parte de gobiernos dictatoriales.

\subsubsection{Expiación}

Gran cuantía de investigaciones jurídicas, con respecto a las finalidades de la pena, optan por omitir una profundización en la doctrina expiatoria o únicamente presentan una breve mención de esta. Profundizar esta doctrina es una labor muy complicada; puesto que es constantemente ignorada por las ciencias jurídicas desde hace ya mucho tiempo. Principalmente, por la razón de que su estudio se ve más relacionado con la teología y su implementación únicamente es posible en el contexto de estados teocráticos, lejanos ya a la estructura democrática moderna. La finalidad de la pena en el cristianismo se erige sobre un constante enfrentamiento entre argumentos bíblicos y argumentos racionales, entre la inmutabilidad del orden establecido por Dios y su mutabilidad, entre la teología cristiana posconciliar y las mínimas, pero existentes migajas de la teología cristiana preconciliar. Sin embargo, en esta doctrina, impera la relación delito-pecado que hoy en día es casi inexistente y mayoritariamente dejada al campo de la religión. Con el pasar de los años, las legislaciones optaron por borrar los pocos escombros de aquellos gobiernos que tenían de núcleo la triada de Estado, religión y derecho.

(14) Por ejemplo, las quemaduras causadas en un individuo, debido a que otro hizo chorrear una taza de café caliente en él.

(15) La cursiva es de Meini (2013). 
Los términos "preconciliar" y "postconciliar" obedecen al desarrollo del Concilio Vaticano II llevado a cabo de 1963 a 1965. Dicho Concilio configuró un punto de quiebre en la teología cristiana. Este nuevo paradigma ocasionó dentro del cristianismo una diferente concepción del delito, del delincuente, de la pena y del Estado en general. Mirándolo así, provocó que en el presente artículo la teología cristiana preconciliar se encuentre entre las teorías absolutas de la pena, mientras que la teología cristiana postconciliar se relacione más con las teorías de la unión.

\section{A) Teología cristiana preconciliar}

La teología cristiana preconciliar se caracteriza por ser extremadamente conservadora y por su percepción estática de la vida y lo que se desarrolla en ella. Se le puede atribuir, en gran parte, el estancamiento de las ciencias (no solo penales), sino como también la opresión de las clases marginadas. Esta opresión nace del amparo del orden social y político dado por Dios, en la medida de que los pobres eran incentivados a no revelarse contra las clases dominantes, para poder así, disfrutar de riquezas en la otra vida. El pecado era considerado una injuria contra el orden de Dios, una violación de sus normas inmutables. Por ello, la finalidad de la pena, tal como comentó Trillhaas (1961), como se citó en Jescheck \& Weigend (1996), "reside en la idea de expiación, sin consideración de fines, orientada exclusivamente al bien mismo, y valida solo para el autor ya que solo mira hacia este" (p. 48).

Para poder indagar más, en los inmensos problemas que trae consigo la teología cristiana preconciliar, es fundamental analizar su mayor fracaso.

\section{(i) Teoría de los dos regímenes}

La teoría de los dos regímenes, lejos de ser un postulado de Paul Althaus (1888-1966), es una interpretación suya de la doctrina luterana de los dos reinos. Es esencial hacer esta aclaración, puesto que Martín Lutero (1483-1546) nunca formuló sistemáticamente una doctrina de "los dos regímenes". Asimismo, autores como Bonhoeffer (2000) afirmaron la imperante obligación de hacer una distinción entre Lutero y sus intérpretes. ¿Por qué es necesaria esta diferenciación? Esta diferenciación es importante debido a que, la interpretación de Althaus (1938), cimentó una visión legitimadora respecto a los eventos ocurridos en el régimen Nazi, posteriormente tildado como la "germanización del cristianismo".

Para otros teólogos, intérpretes y partidarios de la doctrina luterana, como Hansen (2003), la teoría de Althaus (1938) es una “(...) manipulación ideológica (...) del pensamiento de Lutero sobre el accionar creador de Dios" (p. 39). Es por ello que, la interpretación brindada por Althaus (1938) es entendida como "pseudoluterana" o "neoluterana". Pero, ¿de dónde surge esta tergiversación? Para responder esta pregunta, es adecuado remontarse a los escritos de Martín Lutero (1580).

En primera instancia, Lutero (1580) distinguió dos civitas, por un lado, el reino de Dios y, por otro lado, el reino del Diablo (también llamado reino del "mundo"). A rasgos generales, ambos reinos se encuentran en una lucha por el mismo espacio histórico. De acuerdo con Hansen (2003), la teoría de los dos reinos ratificó "(...) la distinción y separación dualista de dos esferas (zwei Räumen) del accionar divino - lo temporal y lo espiritual" (Althaus, 1938, p. 33) ${ }^{(16)}$. Por su parte, Althaus (1938) entendió este postulado de Lutero (1580), no como la existencia de dos reinos, uno de Dios y otro del Diablo, sino como dos regímenes del mismo Dios.

Althaus (1938) postuló la diferencia entre evangelio y ley ${ }^{(17)}$, basándose en su teoría de la "revelación primigenia(18)". Entonces, ¿quién estaba encargado de crear la ley? Para dicho autor, esta no era función del evangelio, sino de lo que él llamaba órdenes, las cuales son: el derecho, el Estado, la economía, el matrimonio y el pueblo. Estas órdenes reciben el evangelio y tienen como objetivo la supresión del pecado. Por esta razón, la distinción fue puesta al servicio de la política del Estado, quien tenía la potestad de castigar a nombre de la ley y del evangelio.

Para esta teoría la ley de Dios se manifiesta, tal como expresó Gonzales (s.f.), "(...) en el ethos de cada pueblo, al que ninguno de sus miembros le es lícito sustraerse, como tampoco de sus exigencias históricas" (p. 240) ${ }^{(19)}$. Por consiguiente, el Führer es el regalo de Dios para un pueblo, con la finalidad de la organización de un

(16) La cursiva es de Hansen (2010).

(17) Este presupuesto (relación evangelio-ley) era el núcleo del argumento de la mayoría de los teólogos contemporáneo a Althaus (1955).

(18) En resumen, la "revelación primigenia" es un relación ya existente y precristiana entre el hombre y Dios; vínculo que permitió que el hombre tenga una comprensión de la realidad divina incluso anterior a la llegada de Jesucristo al mundo.

(19) La cursiva es de Gonzales (s.f.). 
Estado como unidad de un histórico destino. Dios actúa en la política de los pueblos y, por ende, según Althaus (1955) como se citó en Jescheck \& Weigend (1996), "[la finalidad de la pena] reside en sí misma como manifestación de validez del orden eterno y frente al infractor del Derecho" (p. 21). Sin duda, Althaus (1955) desarrolló lo que hoy se concibe como "luteranismo político", al manipular la fe en el destino del propio pueblo y entenderse como la única ley que determina la opción política del individuo.

Es muy claro lo peligrosa que es esta doctrina, no solo por la finalidad que le acuña a la pena, sino también por su legitimización sobre acciones completamente inhumanas y contrarias a los derechos humanos. Igualmente, llama la atención lo imposible de su sustentación en la actualidad, incluso, por la misma religión en la que se originó. Esta postura tan extremista no solo no es usada en el Perú, sino en la totalidad de países del mundo.

\section{B) Problemas de la expiación}

(i) La justicia divina es indemostrable

Si el libre albedrío de la doctrina retribucionista es indemostrable, también, y quizás en más cantidad, lo es la justicia divina. ¿Cómo es posible saber cuál es la voluntad de Dios? Al respecto, Roxin (1976) afirmó que ello no parece corresponder a una verdadera religiosidad; puesto que ¿cómo se puede arrogar que, mediante las sentencias, se manifieste la voluntad divina? Ante una visión en retrospectiva de las sentencias dadas por estados teocráticos, solo queda seguir a Borges (2000) y afirmar que, "quizás los condenaron los hombres, pero no Dios” (p.103).

(ii) Factores que evitan la redención

Dentro de una sociedad existen distintos factores que pueden dificultar e imposibilitar la redención a la que debe aspirar un delincuente en un Estado que acoja la doctrina expiatoria. Un ejemplo claro es la estigmatización ${ }^{(20)}$ que se puede imprimir sobre un determinado condenado o procesado.

(iii) La imposibilidad de moldear religiones fuera de un estado teocrático.

La ética, la moral y la religión no se pueden imponer por la fuerza, algo que en los estados teocráticos sí era posible. En el Perú, tanto la libertad de conciencia como la de religión, se encuentran positivizadas en el artículo 2.3 de la Constitución Política del Perú (1993). Este artículo es el cerrojo que evita la irrupción de sistemas penitenciarios de adoctrinamiento. Cualquier persona puede afrontar la pena internamente de la manera que le plazca o que obedezca a sus creencias. Sin embargo, el Estado no puede pretender conseguir este objetivo sin la voluntad de quien afronta la pena, es decir, de un modo forzoso.

Este problema no es únicamente materia de la doctrina expiatoria; puesto que, si se tiene como presupuesto que la fe es la única forma de sostener el postulado de que un daño pueda ser borrado con la imposición de otro(21), también, el Estado al acoger la doctrina retribucionista, moldearía creencias en los ciudadanos.

(iv) Imposibilidad por parte del Estado de realizar justicia sobre la tierra

Esta doctrina le otorga al Estado la tarea de la realización de la justicia cristiana sobre la tierra. Sin embargo, hoy es dejada para la moral, la ética y la religión. Incluso, si la misión del Estado fuese la de aspirar a una moral cristiana absoluta, esta labor sería completamente ineficiente. En este mismo sentido, Jescheck \& Weigend (1996) aseveraron que "la mayoría del injusto realmente cometido queda, según es conocido, sin castigar" (p. 105).

\subsection{Teorías Relativas}

Figura 2. Teorías relativas

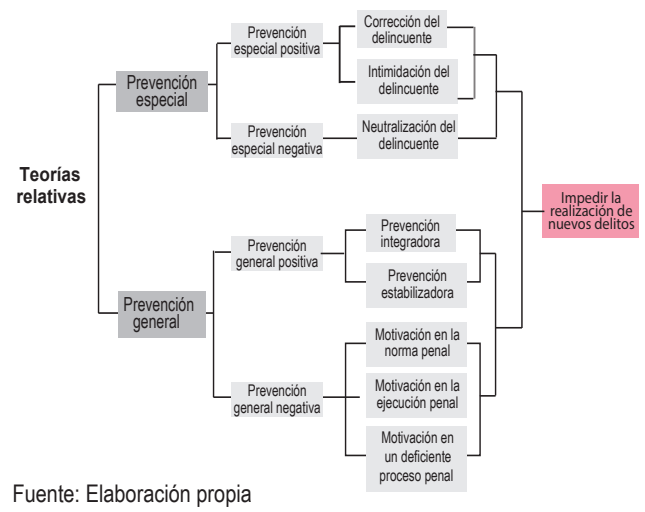

Las teorías relativas, o también llamadas teorías de prevención, no le otorgan fundamentaciones éticas, religiosas o morales a la pena, sino la entienden como un mecanismo para conseguir objetivos ulteriores dentro de la sociedad. Es justo decir que Beccaria (2020) concluyó que el fin principal de una buena legislación es prevenir los delitos antes que castigarlos.

(20) Este factor será analizado más adelante con mayor detalle.

(21) Postura de Roxin (1976). 
El concepto "relativo", según Roxin (1994), proviene del latín referre que significa "referirse a". En estas teorías no se concibe a la pena como "un fin en sí mismo", sino como un medio para otro fin. Según Jescheck \& Weigend (1996) "en las teorías relativas de la pena confluyen, pues, derroteros ideológicos de carácter humanitario, social, racional y utilitarista" (p. 106). Asimismo, no miran al pasado (como los hacen las teorías absolutas), por el contrario, observan a futuro, con el fin de impedir la reincidencia (prevención especial) o la ejecución de nuevos delitos por parte de terceros (prevención general). Las teorías relativas actúan en un instante que difiere al de la imposición de la pena, es decir, actúan o antes de esta última o después. Igualmente, pueden accionarse generalmente sobre la comunidad o sobre el condenado, lo que ocasiona una división bipartita.

\subsubsection{Prevención especial}

Es imposible hablar de prevención especial sin mencionar a Franz von Liszt ${ }^{(22)}$ (1851-1919), su mayor impulsor, y el cambio de paradigma en la criminología ocasionado por su Programa de Marburgo de 1882. Esta doctrina es la que mejor cumple el cometido del derecho penal, como también las exigencias de un Estado social, dado que se protege, tanto al individuo que delinquió como a la sociedad, de la reincidencia delictual. Asimismo, se opta por prescindir de aquellas penas que motiven al sujeto a seguir en esta misma ruta de delincuencia. Liszt (1883) buscó este cometido mediante la corrección, la intimidación y la neutralización; por esto, clasificó al delincuente en tres categorías: el corregible, el intimidable y el incorregible e inintimidable. De este modo, el corregible es resocializado, el intimidable es escarmentado y el inintimidable e incorregible es neutralizado. Esta prevención se consigue a través de la coerción física o por la voluntad del delincuente.

La prevención especial es "la otra cara de la moneda" en relación con la doctrina retribucionista. Para este precepto, la pena no debe ser medida mediante la culpabilidad, sino por medio de la necesidad temporal del tratamiento resocializador. Según Liszt (1883), solo aquella pena que sea necesaria es justa. En este mismo sentido, Beccaria (2020) comentó que, "para que la pena no sea violencia ejercida por uno o por muchos contra un ciudadano particular, debe ser esencialmente pública, pronta, necesaria, la mínima posible en las circunstancias dadas, proporcionada a los delitos y dictada por las leyes" (p. 213).

Debido a que Liszt (1883) dentro de su concepción engloba tanto a la prevención especial positiva como a la negativa, muchos autores optaron por no realizar una distinción entre estos dos tipos de prevención especial. Sin embargo, al Liszt (1883) estar a favor de la pena de muerte y de la cadena perpetua en delincuentes incorregibles e inintimidables, la distinción entre estos tipos de prevención especial se vuelve necesaria. No hay que olvidar que este argumento es el que distingue ambas concepciones.

La prevención especial aportó a los sistemas penales modernos distintas instituciones que benefician al condenado de diversos modos. En el Perú se pueden evidenciar la liberación condicional (art. 42.4 del Código de Ejecución Penal), la semilibertad (art 42.3 del Código de Ejecución Penal), entre otras.

\section{A) Prevención especial positiva}

La prevención especial positiva, que prioriza la reinserción del delincuente, se configura como una herramienta a través de la cual el Estado repara la socialización inicial inculcada en una persona, con la finalidad de desocializarla y volverla a socializar con las normas básicas de convivencia contextualmente imperantes. Este cometido se logra mediante la corrección e intimidación. Igualmente, solo puede bastar socializar eficientemente y omitir la desocialización inicial, si es que el delincuente es primerizo en acciones delictuales, pues no debe cortarse el árbol torcido por completo y volver a ser plantado, sino únicamente debe ser enderezado. Descrito de este modo, pareciese que esta función escapa por completo del campo de acción del derecho penal y la responsabilidad de ella debería caer sobre la organización social, el Estado o el sistema educativo. Sin embargo, es fundamental tener en cuenta que, cuando se fracasa como sociedad, es necesario recurrir al derecho penal.

\section{B) Prevención especial negativa}

La prevención especial negativa, idea expuesta por von Liszt (1883), se centra en la neutralización del delincuente incorregible e inintimidable. El anterior planteamiento surge, debido a que existen delincuentes imposibles de corregir e intimidar, es decir, los que, según la teoría lombrosiana, pueden denominarse "criminales natos". Frente a esto, es necesario priorizar la protección de la sociedad y apartarlos de ella.

(22) Quien es considerado por Roxin (1994) como "el político criminal alemán más significativo" (p. 85). 
Por neutralización deben entenderse aquellas penas que hacen que el delincuente presente una imposibilidad para la comisión de nuevos delitos. Esta imposibilidad se consigue por dos vías: el aislamiento (cadena perpetua) y la eliminación (pena de muerte). Estas vías se encuentran positivizadas en el marco normativo peruano. La eliminación es la forma más efectiva de neutralización, puesto que, a diferencia del aislamiento, la sociedad no debe afrontar los gastos de un delincuente que no tiene la más mínima intención de formar parte de ella.

\section{C) Problemas de la prevención especial}

\section{(i) El cuanto de la pena}

Si esta teoría busca la resocialización, la pena debería ser tan duradera como para posibilitar su concreción. Por ello, para poder sostener esta teoría, sería imprescindible recurrir a penas indeterminadas ${ }^{(23)}$. Debido a que no se recurre al principio de culpabilidad, mediante una justificación resocializadora, podría maniatarse la pena tiránicamente. Se elimina enemigos políticos y se moldea la sociedad a mero gusto y afinidad, esta carencia desemboca en un problema del ius puniendi. De forma similar, al no existir un tiempo límite predeterminado, los individuos estarían bajo la intervención estatal indefinidamente.

\section{(ii) Violación a la conciencia jurídica colectiva}

¿Qué ocurre si no es necesaria la resocialización? De acuerdo con esta teoría, al no usar la culpabilidad y al estar frente a delitos irrepetibles o donde el "enfermo ya esté curado", no será necesaria la imposición de una pena. Un buen ejemplo es el brindado por Roxin (1976) al mencionar a los asesinos de los campos nazis, quienes vivieron discretamente integrados en la sociedad. Otro ejemplo sería el del delincuente que roba una casa, pero se rompe ambas piernas al huir, puesto que surge el interrogante de si ¿también debiera ser castigado? En el primero de los casos el soldado nazi no necesita resocialización alguna $y$, por su parte, en el segundo, el delincuente no presenta un peligro para la sociedad, dado que la reincidencia es simplemente imposible. Si ambos delincuentes no fuesen castigados se mermaría la conciencia jurídica colectiva; puesto que ofrece la apariencia de la inutilidad del Derecho y de la persecución penal, lo que provocaría un efecto adverso al deseado. Incluso, podría incitarse a delinquir, debido a la ineficacia del sistema penal.

\section{(iii) Homo mensura(24)}

Este postulado protagónico resume el principal problema de la prevención especial: la relatividad. ¿Sobre qué actitudes se debe construir la personalidad del sujeto resocializado?, ¿cuál es el objetivo de la resocialización? Sin duda, el ser humano se enfrenta a un problema inmenso, debido a que los sujetos serán resocializados acorde al pensamiento imperante de un Estado y a los valores establecidos en dicha sociedad. En términos más sencillos, si la resocialización se hubiese dado en el régimen Nazi, el individuo sería resocializado según sus principios. Este poder en manos equivocadas podría generar soldados por sobre ciudadanos responsables. El determinar el comportamiento futuro de un individuo es una labor muy delicada, debido a la incertidumbre del futuro. Al respecto, Carnelutti (2019) planteó lo siguiente:

Que una cosa o un hecho sea bien o sea mal depende de lo que viene después. Y el después, del cual depende, no termina nunca. Por eso la ciencia del bien o del mal no es ciencia de los hombres, los cuales no consiguen ver hasta el fondo (p. 57).

Asimismo, tal como lo narró Cury (1988), también se realizaron críticas desde tendencias radicales, las cuales afirmaban que la resocialización era un instrumento para los intereses de una minoría dominante para perpetuar su poder. Según esta tendencia, los valores que se quieren reforzar son aquellos que la clase privilegiada capitalista burguesa desea asentar.

La solución de estos problemas consiste en implantar valores mínimos sobre máximos. Si mediante la prevención especial se trata de inculcar valores genéricos para una adecuada vivencia en sociedad, alejada de toda ideología estatal pasajera, la resocialización tendría sentido. Sin embargo, la estabilización de los valores mínimos es una labor más del derecho penal internacional que del local.

(23) En el caso del Perú existen muy reducidos tipos penales que cumplen estas características. Sin embargo, las penas indeterminadas se encuentran relacionadas con delitos de traición a la patria. Al ser la forma agravada de esta última, regulada por el artículo 328 del Código Penal (1991), un ejemplo de ello.

(24) Homo mensura significa "el hombre es la medida de las cosas", la relatividad que sustenta este postulado es el núcleo de la filosofía de Protágoras y de los sofistas en general. La palabra "hombre" puede ser interpretada de tres maneras: hombre como ser individual, hombre con ser social y hombre como especie. 


\subsubsection{Prevención general}

La prevención general, lejos de ser una teoría moderna, tiene sus primeras evidencias en la formulación clásica que pasó de Protágoras hasta llegar a Grocio "nemo pudens punit, quia peccatum est, sed ne peccetur" (ningún hombre sensato castiga porque se ha pecado, sino para que no se peque). Es necesario dividir este tipo de prevención en: prevención general positiva y prevención general negativa. Mientras que la primera busca influir sobre la totalidad de los ciudadanos, brindándoles así una sensación de seguridad. La segunda, busca influir únicamente sobre los individuos en peligro de realizar actos delictivos.

\section{A) Prevención general positiva}

De acuerdo con esto, Roxin (1994) distinguió tres efectos y fines distintos en la prevención general positiva: (i) el efecto de aprendizaje; (ii) el efecto de confianza; y (iii) el efecto de pacificación. Debido a ello, es necesario dividir la prevención general positiva en dos visiones, de un lado la visión integradora y de otro la visión estabilizadora.

(i) Prevención integradora

La visión integradora usa la pena como la afirmación del derecho ante los ojos de la colectividad. Uno de sus máximos exponentes es Luhmann (1998). Desde esta perspectiva, la pena puede ser utilizada para reforzar costumbres, afirmar conciencia, conservar el orden y fortalecer normas jurídicas. Cabe diferenciar este precepto de la visión hegeliana retributiva, dado que esta última busca la afirmación del Derecho en el que se tiene como fin el Derecho mismo. En cambio, la visión integradora reafirma el Derecho para que pueda ser percibido por la colectividad. Sumado a esto, la visión integradora ratifica la conciencia social mediante la impresión colectiva de la reacción que tuvo el Estado frente al delito. En palabras sencillas, se busca dar a la sociedad la impresión de que el Estado "sí realiza su trabajo", lo que ocasiona que este último adquiera la confianza de la sociedad y así consiga que esta respete el Derecho.

\section{(ii) Prevención estabilizadora}

La visión estabilizadora usa la pena para restablecer la vigencia de la norma. Este postulado tiene rasgos similares con la visión hegeliana de las teorías absolutistas. Es tan grande el parecido que algunos autores optaron por llamar "neo-retribucionistas" a sus partidarios ${ }^{(25)} \mathrm{O}$, incluso, por considerar este punto de vista dentro de otras doctrinas. Sin embargo, es adecuado realizar un análisis y saber cuál es la diferencia respecto al postulado hegeliano.
Para Jakobs (1991), "la misión de la pena es el mantenimiento de la norma como modelo de orientación para los contactos sociales $^{(26) " ~(p . ~ 14) . ~ C l a r o ~ e s t a ́, ~ a ~ d i f e r e n c i a ~ d e ~}$ la visión, hegeliana que intenta la reafirmación de la voluntad general representada en el marco normativo. Hegel (1821) no buscó fines ulteriores dentro de la sociedad; en cambio, Jakobs (1991) intenta proporcionar un modelo de orientación a los contactos sociales. Habría que hacerse la pregunta: ¿qué son los contactos sociales? La respuesta es fácil, son aquellas relaciones entre individuos dentro de una sociedad. La norma tiene la función de hacer predecibles los comportamientos dentro de estas interacciones, en la medida de que solo son posibles los contactos sociales si una persona no está pendiente de que un individuo tendrá un comportamiento impredecible.

Por ello, para Jakobs (1991), que una conducta contradiga una norma es una infracción de esta. No se puede ignorar que la pena es "la réplica ante la infracción de la norma" (p.13). Entonces, ¿dónde se encuentra la función preventiva? Para Jakobs (1991), la función preventiva de la pena se halla en la protección de las condiciones de la integración social. Esta función preventiva no está vinculada con la protección de bienes jurídicos, sino con la reafirmación de la vigencia de la norma. Por medio de la reafirmación de esta última se consigue la integración social.

\section{B) Prevención general negativa}

Meini (2013) planteó que la teoría preventiva general negativa se encarga de dar disciplina al individuo, a diferencia de la teoría de la prevención especial que lo educa. Por consiguiente, esta teoría respeta la libertad de pensamiento y evita el adoctrinamiento; ambos presupuestos necesarios para la constitución de un Estado de Derecho.

Esta teoría deja de lado la culpabilidad (imprescindible en las teorías absolutas)

(25) En este sentido véase Duran (2011).

(26) Jakobs (1991) se alejó de la concepción de su maestro Hans Welzel (1904-1977), puesto que para el primero el derecho penal llega muy tarde para evitar lesiones de bienes jurídicos, mientras que para Welzel esta es su finalidad. Es por ello que, Villavicencio (2019) realiza una distinción entre la concepción de ambos autores, llamando versión ética a la welzeniana y versión sistemática a la jakobsiana. 
y la remplaza por la motivación conseguida mediante la intimidación. La pregunta que surge a continuación es ¿en qué momento debe verificarse esta motivación? De acuerdo con Bentham (1830), esta se da en la ejecución penal; según Feuerbach (1989), surge en la norma penal y, para el presente artículo, se da en un deficiente proceso penal. A continuación, se analizan estas posturas.

\section{(i) En la ejecución penal}

Jeremy Bentham (1748-1832) manifestó que la sociedad no se ve intimidada por la pena establecida en la norma, sino por la percepción de la ejecución de la pena. Este filosofo inglés postula que, cuando el individuo ve la forma en que los condenados cumplen sus penas, es disuadido a cometer delitos. Así pues, la arquitectura panóptica penitenciaria ${ }^{(27)}$ es la cúspide de este pensamiento. El utilitarismo benthamiano, instaurado mediante su obra "Una introducción a los principios de la moral y la legislación" (1789), busca el bienestar social por sobre cualquier finalidad. Por esta razón, utiliza el valor de cada placer y dolor para calcular la utilidad individual y colectiva.

Para Bentham (1789), los derechos humanos no son inmutables o inalienables, sino solo defendibles siempre y cuando no limiten la utilidad social. Por ello, se encuentran un escalón bajo el utilitarismo. El panóptico de Bentham, lejos de ser solo una mera idea arquitectónica, "es la materialización coherente de un modelo moral sobre la sociedad que, en último extremo, está abocado a limitar el alcance de los derechos humanos, apuntando a su instrumentalización y relativización histórica o cultural" (Beytía, 2017, p. 193). La filosofía benthamiana se concretó en diversas partes del mundo. Un ejemplo sudamericano es Chile, donde se construyeron 58 panópticos para albergar viviendas sociales. Cabe destacar que las principales críticas a la doctrina de Bentham (1789) se deben a la incompatibilidad con los derechos humanos. Dichas críticas surgieron desde el primer día de su introducción, puesto que ese mismo año se llevó a cabo la Declaración de los Derechos del Hombre y del Ciudadano (1789).

Finalmente, es determinante realizar una distinción entre lo que es la pena y lo que genera la pena. Es más sostenible pensar que lo que disuade a un sujeto no es la pena en sí, sino lo que esta genera. Un ejemplo podría ser la prisión privativa de libertad, en el que el hecho de ver a un hombre tras las rejas no intimida; lo intimidante es observar a un hombre alejado de su familia, amigos, sin trabajo y estigmatizado, es decir, lo que ocasiona la pena.

\section{(ii) En la norma penal}

Esta visión sostenida por Anselm von Feuerbach $^{(28)}$ (1775-1833) parte del vínculo entre el mensaje de la norma penal y los ciudadanos $^{(29)}$. Para este autor, la infracción de la ley surge de la "sensualidad", es decir, por el placer proveniente de la acción. Para los partidarios de esta doctrina en toda acción delictiva existe una ponderación de costos y beneficios $^{(30)}$.

Asimismo, sostienen que la motivación hace que el tipo penal tenga como objetivo describir la conducta prohibida y motivar su no realización. Esto se consigue a través de la "coacción psicológica". Ergo, es la amenaza de que el mal por recibir será mayor que el disgusto causado por la no realización de la acción típica penal, en pocas palabras, se busca la intimidación. Para Feuerbach (1989), a diferencia de Bentham (1830), la ejecución de la pena solo hace evidente la seriedad de la amenaza de la norma penal.

En este postulado se pueden encontrar dos enormes errores estructurales. EI primero de ellos es la imposibilidad de un conocimiento generalizado de la norma penal en la ciudadanía, puesto que, ¿cómo podría un individuo tener esta vinculación psicológica si nunca leyó el Código Penal? o ¿cómo se justificarían los crímenes pasionales, en los cuales el individuo se ve motivado por un impulso momentáneo, por sobre una ponderación entre el mal que podría recibir y el disgusto de la no realización de la acción? El segundo problema estructural se fundamenta en la ponderación favorable a la comisión del delito, es decir, ¿qué ocurre si los beneficios de cometer el delito son mayores a la pena por cometerlo? ${ }^{(31)}$. Frente a esto, la única solución en estos casos sería la de

(27) Esta arquitectura presenta un edificio rodeado de forma circular por otro. Los inspectores ocupan el edificio central, mientras que los presos ocupan el edificio que los rodea. Debido a ello, los inspectores tienen la facilidad de vigilar a los presos sin que ellos puedan saberlo y, claro está, tienen la posibilidad de poder observar a cada uno de ellos al mismo tiempo.

(28) Considerado por Jescheck \& Weigend (1996) como "el más grande de los criminalistas alemanes de la primera mitad del siglo XIX" (p.107).

(29) En este mismo sentido véase Silva (2015).

(30) Véase Becker (1968). 
elevar las penas, lo que provoca una desproporción innecesaria y, consecuentemente, una ejecución penal deshumanizadora.

Según Jakobs (1991), la postura manifestada por Feuerbach (1989), parte de una base equivocada, que es medir el beneficio potencial del delincuente y compensarlo mediante un mal. Así pues, se deja de lado el daño que la acción produce al orden social. De acuerdo con Jakobs (1991), este error produce una desproporción respecto a las penas, debido a que perfectamente una difamación, en un contexto determinado, podría significar una gran pena debido al quantum del beneficio. Asimismo, en la otra parte, un delito de alto riesgo social y beneficio insignificante significa una pena extremadamente reducida. Esto desencadena en la supresión de la parte especial de Código Penal (1991) y en su posterior cambio por nuevos grupos en función al quantum del beneficio.

Finalmente, se puede concluir que la visión de Feuerbach (1989) únicamente serviría cuando el individuo comete el delito teniendo conocimiento de la norma y sin ningún impulso pasional o factor externo que hayan evitado una ponderación consciente entre el disgusto y la pena. Al respecto, diversos estudios muestran un panorama contrario, uno de los más importantes fue el realizado por David Anderson bajo el nombre de "The Deterrence Hypothesis and Picking Pockets at the Pickpocket's Hanging" (2000). En dicho estudio, llevado a cabo entre 1997 y 1999, se recogieron datos a partir de 278 entrevistas a reclusos varones que cumplían una pena dentro de dos centros penitenciarios. La conclusión de este estudio fue que el $76 \%$ de los delincuentes muestreados y el $89 \%$ de los más violentos no eran conscientes ni de los posibles castigos, ni de las posibilidades de ser aprehendidos. Esto reduce mínimamente la eficacia de esta teoría, en el caso más optimista, tal como lo afirmó García (2006), para los llamados delitos de derecho penal económico.

\section{(iii) En un deficiente proceso penal}

La prevención general inconsciente -teoría propuesta por el presente artículo-, hace que esta distinción (prevención general negativa en el proceso penal) sea necesaria, puesto que es en este momento en el que puede verificarse la motivación. Esta concepción, lejos de ser una propuesta teórica, es una lamentable realidad pragmática. En el Perú, la intimidación, más que por la norma o por ejecución penal, se consigue gracias a un proceso ineficiente que da cabida a la estigmatización y la presión mediática ${ }^{(32)}$. Debido a estos problemas, la intimidación no se produce fundamentalmente tras la sentencia o en la ejecución penal, sino en el propio proceso.
Un proceso ineficiente produce una intimidación particular, en la medida de que el sujeto se ve disuadido a la comisión de delitos por miedo a la estigmatización, a la presión mediática y a las arbitrariedades que reinan en los procesos penales. Mirándolo así, ocasiona que lo que disuada al individuo no sea la pena, sino la destrucción de su honor y dignidad. Desgraciadamente, este efecto termina convirtiéndose en una triste realidad en muchos países y demuestra el fracaso de la prevención general positiva (la colectividad deja de confiar en el Derecho), a tal punto, que genera una prevención general negativa (la colectividad empieza a temer al Derecho).

Algo que también debe aclararse es que, de la prevención general inconsciente no se salva absolutamente nadie, pues cualquiera puede caer en manos de la administración de justicia, haciendo más triste el panorama al que los individuos deben hacer frente.

\section{C) Problemas de la prevención general}

(i) El cuanto de la pena

Al igual que en la prevención especial, esta teoría deja de lado el principio de culpabilidad al momento de determinar la duración de la pena. Esto ocasiona que exista incertidumbre sobre el máximo y el mínimo de una determinada pena, lo cual torna su finalidad cada vez más maquiavélica. Pues, tal como comentó Roxin (1976), “(...) quien quiere intimidar mediante la pena, tenderá a reforzar ese efecto castigando tan duramente como sea posible" (p. 19). Esto causa, dentro de la sociedad, más daño que beneficio.

(ii) Viola la dignidad humana

Debido a que se usa a un individuo para intimidar a la colectividad, se está frente a la instrumentalización del ser humano tan repudiada por los partidarios retribucionistas (como Kant y Hegel). Estos lo relacionan como una violación a la dignidad del hombre. En este mismo sentido, Wessels, Beulke y

(31) En este sentido, García (2006) usa de ejemplo la estafa. Dicho tipo penal regulado por el artículo 196 del Código Penal (1991) tiene una pena máxima de seis años. Perfectamente, podría conseguir su objetivo intimidatorio si se habla de cantidades económicas mínimas. Sin embargo, si el bien mueble o inmueble, que es objeto de estafa, da una remuneración económica muy alta, este tipo penal puede, incluso, causar un efecto totalmente adverso al descrito por Feuerbach (1989).

(32) Ambos conceptos son desarrollados más adelante. 
Satzger (2018) afirman que "(...) las posiciones preventivas (con excepción de la prevención especial positiva) representarían un peligro de instrumentalización del autor ("chivo expiatorio") para satisfacer las necesidades sociales y lesionaría con ello su dignidad" (p. 11).

(iii) El qué

Las teorías preventivo generales, explican muy bien el cuándo, porque acogen un normativismo estricto. Sin embargo, presentan problemas en relación al qué. Pues, ¿qué conductas deben ser motivadas mediante la amenaza penal? Al respecto, García (2019) sostuvo lo siguiente:

No puede dejar de aceptarse cierto decisionismo a la hora de fijar la frontera entre lo que se puede motivar mediante la amenaza penal y los límites a esta motivación, lo que, por otra parte, la hace muy sensible a situaciones emotivas o subjetivas de la comunidad. Una muestra clara de esta situación se aprecia en los delitos que afectan la seguridad ciudadana (p. 83).

\subsection{Teorías de la unión}

Figura 3. Teorías de la unión

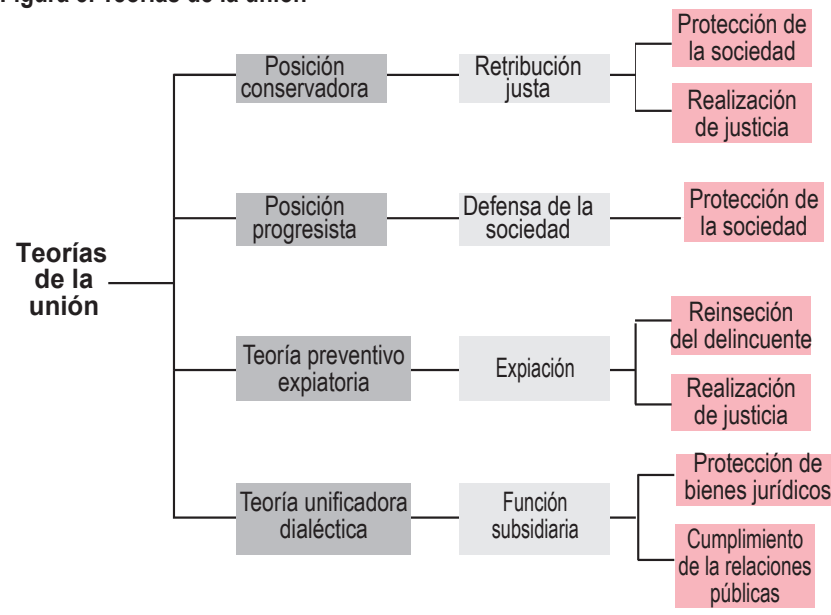

Fuente: Elaboración propia

Las teorías de la unión, conocidas como teorías mixtas o eclécticas, están en la búsqueda de un equilibrio ponderado entre justicia y utilidad. Es a Adolf Merkel (1899) a quien se le atribuye el inicio de estas teorías. Mir Puig (2016) aseveró que las teorías eclécticas tienen en común la búsqueda de la protección de la sociedad. Sin embargo, esta es la única coincidencia entre estas corrientes, fruto de ello, la necesaria división al momento de su análisis.

\subsubsection{Posición conservadora}

Esta posición conserva los fundamentos de la doctrina retribucionista, en la medida de que predomina el carácter retributivo de la pena por sobre cualquier tipo de prevención. Asimismo, debido a que presenta un cambio minúsculo respecto a la teoría retributiva, todos los problemas que posee dicha doctrina son evidentes en esta ${ }^{(33)}$. La posición conservadora busca proteger a la sociedad mediante una retribución justa, es decir, aplica la pena proporcionadamente a la culpabilidad. Sin embargo, al momento de la determinación de la pena, la prevención especial y la prevención general, son usadas como complementos de la retribución. Es por ello que, según Mir Puig (2016), para esta posición “(...) el Derecho penal está llamado a cumplir una doble función, no solo de protección de la sociedad, sino también de realización de la justicia (...)" (p. 95).

\subsubsection{Posición progresista}

Para esta perspectiva, a diferencia de la posición conservadora, al Derecho penal solo le importa la protección de la sociedad. Dicho fin, únicamente puede ser conseguido mediante un consenso entre prevención especial y prevención general; situación en la que la retribución solo tenga la función de marcar el límite máximo de la pena, la cual busca una función preventivo especial. Dicho de otro modo, la pena puede ser muy reducida en relación con la culpabilidad, si la prevención especial lo amerita. Sin embargo, se carece de un límite mínimo, lo que ocasiona que la gran cantidad de problemas de la prevención especial sean evidentes en esta posición ${ }^{(34)}$.

\subsubsection{Teoría preventivo expiatoria}

Francesco Carnelluti (1879-1956), unos de los mejores procesalistas de la historia, es quien apoya esta teoría. Carnelluti (2019), quien consideró como núcleo la religión cristiana, afirmó que "[...] sin fe es vano pensar en hacer ciencia y mucho menos ciencia del derecho y menos aún ciencia del derecho penal" (p. 693).

(33) Véase la página 8.

(34) Véase la página 15. 
Para Carnelluti (2019), la pena, lejos de ser un mal, es un tratamiento para el espíritu, el cual se consigue mediante cinco etapas:

a) Observación: en esta primera etapa, el condenado debe ser observado tanto corporal como espiritualmente.

b) Aislamiento: se consigue al separar al condenado del ambiente social externo, de sus bienes, libertad y trabajo; induce su inmersión en la plegaria, puesto que, para este autor, "[...] sin la plegaria el hombre no puede liberarse (p. 692)".

c) Humillación: se obtiene por medio de la denominación del condenado, su tratamiento verbal, su vestimenta y la constante vigilancia; esta humillación tiene como finalidad eliminar aquellos valores que impulsaron al delincuente a cometer el delito.

d) Disciplina: se logra gracias a los poderes asignados a los oficiales, quienes tienen la finalidad de conseguir que el condenado obedezca las normas y los reglamentos. Asimismo, para este fin, existen castigos y premios que dependen de su actitud.

e) Asistencia del condenado: en palabras de Carnelluti (2019), es "el corazón del problema penal" (p. 702). Resulta cuando, quien está al lado del recluso, es un hermano que, por medio de gran vocación, lo impulsa a salir adelante.

Esta teoría de Carnelluti (2019), a diferencia de la expiatoria absolutista (teología cristiana preconciliar), sí está tras una prevención especial en el individuo, la cual se logra con la expiación del pecado y con la ayuda del sistema penitenciario. Lamentablemente, los problemas de esta teoría son una suma de los problemas de las teorías absolutas expiatorias y los problemas de la prevención especial. Salta a la vista la imposibilidad de moldear creencias mediante el sistema penitenciario, dado que la voluntad divina es indemostrable $\mathrm{y}$, a su vez, existe un obstáculo en el cuánto de la pena y la violación en la conciencia colectiva, a causa de que no todas las personas en el mundo ven el delito y la pena desde una concepción cristiana ${ }^{(35)}$.

Sin lugar a dudas, el planteamiento de Carnelluti (2019) es una mera concepción utópica que brinda las mejores reflexiones respecto a la forma en que debería ser un sistema penitenciario que apoye la resocialización del delincuente, dado que para Carnelluti (2019):

Ir hacia los reos es la solución. No huirles; sino correr a su encuentro, como Francisco. No mirarlos de arriba abajo, sino apearse del caballo para adaptarse a ellos, como Francisco. No apartar la mirada de su deformidad; sino sostener la vista, como Francisco. No taparse la cara, por temor de contagio; sino besarlos en la cara, como Francisco. No detestarlos como enemigos, no darles latigazos como a perros, no ponerle al cuello la campanilla del leproso, Su enfermedad no es más que hambre y sed, frio y soledad. El alimento para quitarles el hambre, el agua para quitarles la sed, la tela para vestirlos de nuevo, la casa para alojarlos, es nuestro amor. El antídoto contra el mal es el bien. Y esta medicina milagrosa no es de aquellas que los hombres deban buscar con fatiga o pagar a peso de oro; no es necesario, para encontrarla, más que querer bien. Por eso, en la lucha contra el delito, es fácil conquistar la victoria, siempre que los hombres escuchen la última palabra del Maestro: jamaos como yo os he amado! (p. 63) (36).

\subsubsection{Teoría unificadora dialéctica}

La teoría sostenida por Roxin (1976) asume el nombre de "dialéctica", debido a que reúne los puntos de vista de las teorías retribucionista y preventiva mediante una síntesis. Roxin (1976) le atribuye a la pena la finalidad de protección de bienes jurídicos y el aseguramiento de las relaciones públicas, lo cual afirma, como consecuencia de ello, la naturaleza subsidiaria del Derecho. Este objetivo se consigue dándole a la pena funciones distintas en diversos estadios. De manera que se pone fin al problema sobre si priorizar la prevención o la retribución. Es así que Roxin (1976) le asigna a la pena la siguiente aplicación:

a) En la conminación aplica la prevención general.

b) En la aplicación judicial aplica la prevención especial, la prevención general y la retribución.

c) En la ejecución condenatoria se implementa la prevención especial.

En el primer momento, la pena tiene la función de proteger los bienes jurídicos y las prestaciones públicas, por ello, surge de la subsidiariedad $^{(37)}$. La pena, dentro de esta fase, únicamente prioriza ello, debido a que ninguna teoría aclara que es considerado un delito. Consecuentemente, para proteger

(35) Cada uno de estos problemas ya fueron analizados, tanto en el apartado de la doctrina expiatoria absolutista como en el de prevención especial.

(36) Las cursivas son de Carnelluti (2019).

(37) Igualmente, la función subsidiaria evita que el legislador castigue delitos inmorales que no dañen bienes jurídicos o el aseguramiento de las relaciones públicas. 
estos dos elementos, se le da una finalidad preventivo general a la pena.

En el segundo momento, se refuerza la prevención general a través de la imposición de la pena y se demuestra así la seriedad de la ley. En esta aplicación judicial, se debe buscar la prevención especial, pero se tiene como límite la culpabilidad del autor (retribución). Sin embargo, el castigo puede ser perfectamente establecido por debajo de dicha culpabilidad por motivos preventivos especiales, pero siempre y cuando la prevención general lo permita ${ }^{(38)}$. Cuando colisiona la prevención especial y la general, se debe priorizar la prevención especial, debido a que, según Roxin (1994), cuando predomina la prevención general por sobre la prevención especial, esta última ve amenazada su utilidad. Caso contrario ocurre si se prioriza la prevención especial por sobre la prevención general, dado que esta última no ve afectada su utilidad.

La última fase debe enfocarse en la reincorporación del delincuente, en el que se aplica la prevención especial. Asimismo, dicha ejecución reafirma todos los fines acuñados a la pena en las etapas anteriores.

En resumen, para Roxin (1994), la pena tiene una finalidad preventivo especial y preventivo general. La pena se asigna acorde con la prevención especial y se tiene como límite máximo la culpabilidad del autor (retribución) y como límite mínimo la conciencia colectiva (prevención general).

Al igual que todas las teorías analizadas, tal como lo sostiene García (2019):

(...) la teoría dialéctica de la unión ha sido igualmente objeto de criticas por la preminencia de la finalidad preventiva o la falta de explicación de por que el principio de culpabilidad limita la disuasión al momento de imponerse la pena (p. 91).

Sin embargo, a pesar de estas críticas, la teoría unificadora dialéctica es el postulado actual con mejor planteamiento teórico, debido a que usa perfectamente cada uno de los aportes y principios de otras teorías y las fusiona para formar una teoría sólida y funcional. Es por ello que, esta teoría cuenta con el mayor respaldo, tanto en la doctrina internacional, como en la nacional.

\section{4. ¿Qué teoría adopta el Perú?}

\subsection{Marco normativo}

Dentro del artículo 139, correspondiente al capítulo VIII de la Constitución Política del Perú (1993), se establece lo siguiente:
Artículo 139.- Son principios y derechos de la función jurisdiccional.

(...) 22. El principio de que el régimen penitenciario tiene como objeto la reeducación, rehabilitación y reincorporación del penado a la sociedad [énfasis agregado].

Figura 4. Que teoría adopta el Perú

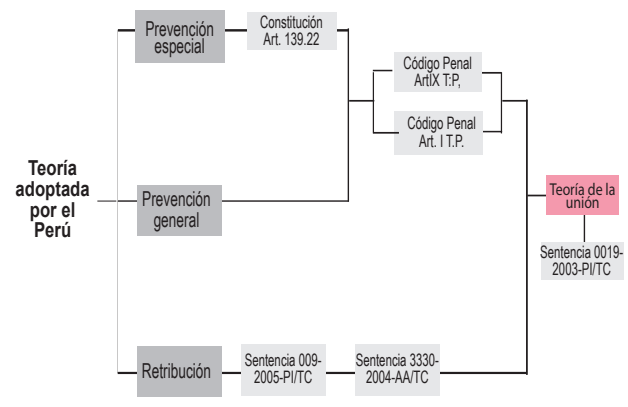

Fuente: Elaboración propia

En este mismo sentido, el artículo IX del Título Preliminar del Código Penal (1991) instaura lo siguiente:

Art. IX.- Funciones de la Pena y medidas de seguridad.

La pena tiene función preventiva, protectora y resocializadora. Las medidas de seguridad persiguen fines de curación, tutela y rehabilitación [énfasis agregado].

En el artículo 139 de la Constitución (1993) se decreta que la ejecución de la pena debe priorizar la reinserción del delincuente en la sociedad (reeducación, rehabilitación y reincorporación). De igual manera, el art. IX del T.P del Código Penal (1991) le atribuye a la pena una función preventiva (prevención especial y prevención general), una función protectora (prevención especial negativa) y resocializadora (prevención especial positiva).

En este mismo sentido, el articulo I del título Preliminar del Código Penal (1991) establece lo siguiente:

Art. I.- Finalidad Preventiva

Este Código tiene por objeto la prevención de delitos y faltas como medio protector de la persona humana y de la sociedad [énfasis agregado].

(38) Un ejemplo claro es el de los soldados nazis reinsertados en la sociedad, al que constantemente se recurre dentro de este artículo. En dicho ejemplo la prevención general no permite que por motivos preventivos especiales se omita una pena. Debido a que, de ser así, se vulneraría la conciencia social y la confianza en el Derecho. 


\subsection{Jurisprudencia}

El Tribunal Constitucional en la Sentencia 009-2005-PI/TC se pronunció respecto a cada una de las teorías de la pena y concluyó lo siguiente:

a) Las teorías retributivas carecen de todo sustento científico y niegan la dignidad humana, reconocida en el artículo 10 de la Constitución Política del Perú (1993). Sin embargo, no se desconoce que toda pena lleva consigo un elemento retributivo.

b) Las teorías preventivas (especial y general) respetan la dignidad y estas se convierten en el mejor medio para reprimir el delito.

En la primera conclusión de esta sentencia, el Tribunal Constitucional reconoce que toda pena lleva consigo un elemento retributivo, el cual debe ser interpretado como el principio de culpabilidad. Asimismo, en la sentencia 33302004-AA/TC, el Tribunal Constitucional acoge el concepto kantiano de dignidad, afirmando que "la persona, pues, está consagrada como un fin es sí misma y, por ende, el Estado tiene la obligación de protegerla" (fundamento 45).

\subsection{Respuesta}

Al tener claro esto, es posible resolver la pregunta planteada por este apartado. La teoría adoptada por el Perú es una teoría de la unión, debido a que, en el marco normativo y en la jurisprudencia del Tribunal Constitucional, se reconocen las teorías preventivas, como también diferentes elementos retributivos. Sin embargo, es correcto preguntarnos. ¿Cuál de todas las teorías eclécticas es la aplicada? La teoría de la unión que se acoge en el Perú, es la teoría unificadora dialéctica de Roxin (1976), por los motivos que se explicarán a continuación.

En primer lugar, en la etapa de la conminación (prevención general) se ve aplicada tanto la disposición del art. IX, como la del art. I del T.P del Código Penal (1991). Asimismo, se aplica una prevención general inconsciente, con motivación en el proceso penal.

En segundo lugar, en la aplicación judicial, se prioriza la prevención especial, prueba de ello, son los siguientes artículos:

a) El artículo 45 del Código Penal (1991), en el cual se tipifica que, los jueces deben considerar las carencias sociales, la cultura y costumbres y los intereses de la víctima; al momento de determinar la pena.

b) El articulo 46.1 del Código Penal (1991), en el cual se regulan circunstancias de atenuación. Donde se consideran elementos como la carencia de antecedentes penales y la edad del imputado.
En relación a la culpabilidad como limite máximo, el Tribunal Constitucional en la sentencia 0019-2005-PI/TC sostuvo que:

Es preciso destacar, sin embargo, que ninguna de las finalidades preventivas de la pena podría justificar que exceda la medida de la culpabilidad en el agente, la cual es determinada por el juez penal a la luz de la personalidad del autor y del mayor o menor daño causado con su acción a los bienes de relevancia constitucional protegidos. (fundamento 41)

Asimismo, en esta misma sentencia, el Tribunal Constitucional, también hace referencia a la prevención general como límite mínimo, afirmando que "[...] ninguna medida tendiente a la resocialización del imputado (prevención especial), podría anular el efecto preventivo general, sobre todo en su vertiente positiva (...). (fundamento 42)

c) Finalmente, en la ejecución condenatoria, se aplica el articulo 139 de la Constitución Política del Perú (1993) y el art. IX del T.P del Código Penal (1991).

Como ya se mencionó con anterioridad( ${ }^{(39)}$, la teoría unificadora dialéctica, fue criticada debido a la gran importancia que le brinda a la prevención especial. Pues, la prevención especial comprende el núcleo de la fundamentación de Roxin (1976) y es un elemento indispensable, tanto en la aplicación judicial, como en la ejecución condenatoria. Debido a ello, es necesario preguntarse si se cumplen los objetivos preventivos especiales que ostenta la pena en el marco normativo peruano. Sin lugar a dudas, la respuesta correcta es negativa. Enseguida se analizan cada uno de los problemas que evitan su materialización.

\section{Problemas que impiden una adecuada prevención especial en el Perú}

\subsection{Estigmatización del delincuente}

Contrario a lo que se piensa comúnmente, una pena no culmina con el fin que judicialmente

(39) Véase la página 25. 
se le establece; esta finaliza muchos años después o, incluso, en la mayoría de los casos, nunca tiene un fin. Esto se debe a la estigmatización que recibe el individuo después de haber recibido una determinada pena. Según Goffman (1986), como se citó en Pérez (2013), "un estigma es un atributo que desacredita a un individuo, que lo reduce de una persona completa y común a una marcada y disminuida" (p. 295). Esta etiqueta hace que las personas que la posean se distingan de los demás, sintiéndose desvalorizadas, prejuzgadas y excluidas por la sociedad. La denominación de "delincuente" conferida al infractor de la ley penal, si bien no puede ser utilizada antes de la sentencia, tampoco debería ser empleada una vez finaliza la pena judicial. Lamentablemente, este título permanece como una cicatriz imborrable en el ciudadano, la cual, lejos de ser visible al ojo humano, es invisible para él, pero es manifiesta ante los ojos de la sociedad.

La estigmatización, lejos de ser una problemática en las teorías retribucionistas y preventivas generales, beneficia la concreción de sus finalidades. En el caso de la primera, la estigmatización es una parte primordial del castigo y, en el caso de la segunda, la estigmatización promueve la función disuasiva de la pena. Empero, el efecto que esta produce en la prevención especial es completamente perjudicial a la resocialización del individuo ${ }^{(40)}$. Tras todo esto, es evidente lo imposible que es pretender buscar la reinserción de alguien que delinquió, sin antes cambiar la percepción que la sociedad tiene sobre él(41).

\subsection{Presión mediática}

La espina dorsal de todo Estado democrático moderno es, en definitiva, la separación de poderes (poder legislativo, poder ejecutivo y poder judicial). Esta tripartición tiene como progenitor al barón de Montesquieu, cuyos esbozos fueron ilustrados en su tratado El espíritu de las leyes (1748). Siglos después, los aportes de esta obra son evidentes y plausibles en la actualidad, puesto que de ella emana el principio de independencia judicial. Este concepto debe ser comprendido, tal como expresó San Martin (2020), como un medio para llegar a la imparcialidad, mas no como un fin. Es por ello que, según este autor, la independencia es "una garantía básica de los jueces, en cuya virtud tienen plena libertad de decisión en la interpretación y aplicación del sistema de fuentes, sin que nadie pued[a] inmiscuirse en su actuación para influir o condicionar sus resoluciones" (p. 131). La imparcialidad judicial no se limita únicamente a aquella que debe existir entre los poderes del Estado, sino también frente a las partes y, por supuesto, a la sociedad.

Esta independencia debe ser total y debe carecer de total legitimidad una cuasi-independencia o semi-independencia.
Si no es así, las sentencias judiciales no buscarán justicia, sino mera arbitrariedad. Es por ello, que el inciso segundo del artículo 139 de la Constitución Política del Perú (1993) manifiesta lo siguiente:

Artículo 139.- Son principios y derechos de la función jurisdiccional.

(...) 2. La independencia en el ejercicio de la función jurisdiccional. Ninguna autoridad puede avocarse a causas pendientes ante el órgano jurisdiccional ni interferir en el ejercicio de sus funciones (...). [énfasis agregado].

Sin embargo, al estar en un mundo cada vez más mediatizado, donde la libertad de expresión se encuentra en su cúspide, distintos procesos no escapan de ser mediatizados desproporcionadamente y seguidos excesivamente. Es ahí, cuando se crea un juicio adicional al judicial, uno que puede ser denominado "juicio mediático"(42). Los juicios mediáticos se manifiestan como un proceso paralelo, adicional al proceso jurídico, donde, por lo general, los involucrados son funcionarios públicos importantes, individuos populares o ciudadanos que fueron acusados de cometer un delito en un contexto particularmente llamativo para la colectividad. Ejemplos de este tipo en el Perú son "pan de cada día". Lo característico de este tipo de procesos es que, las garantías son sencillamente pisoteadas y los principios constitucionales mermados; donde es totalmente normalizada la violación a la presunción de inocencia.

Cuando se está frente a un juicio en el que median exfuncionarios, ya enjuiciados por la colectividad y por los medios de comunicación, es cuando hay un enfrentamiento a uno de los problemas más grandes de las ciencias penales actuales. Es ahí, cuando el juez es arrinconado; por un lado, tiene al imputado y a su abogado defensor y del otro, al fiscal y a la muchedumbre enardecida. En este contexto, lamentablemente tan común en el país, es cuando no solo la independencia, sino también la imparcialidad pende de un hilo. La presión mediática y social es tan fuerte que los

(40) Véase al respecto Pérez (2013).

(41) Pareciese que la sociedad peruana, que de acuerdo con el INEI (2017), el 76 \% de peruanos confiesa la religión católica, olvido que, en los relatos bíblicos, su "Salvador" fue considerado un delincuente y penado como tal.

(42) Véase al respecto Harbottle (2017). 
jueces deben decidir entre si buscar la justicia en el proceso sin importar quien esté frente a ellos o, en contraposición, contentar a la muchedumbre con una sentencia muchas veces arbitraria. Mas que un error es una aberración pensar que el meter a un inocente a la cárcel para contentar a la muchedumbre enardecida tiene fines preventivo generales positivos. Entonces, ¿por qué en el Perú un juez permite que su decisión se vea completamente parcializada por la opinión colectivamente imperante? La respuesta es simple, por los tres motivos del oidor: "por miedo, por miedo y por miedo" (Palma, 1872, p. 95).

La pregunta que ahora hay que hacer es: ¿en que afecta todo ello a la prevención especial? Cuando los medios hacen algún tipo de "juicio de valor" sin la existencia de ninguna sentencia judicial, se estigmatiza a un procesado; aspecto que hará sencillamente imposible su reinserción en la sociedad. Pareciera que el temor de la pena, la incertidumbre del juicio, la privación de derechos y el daño a la esfera familiar no fuesen suficientes; a todo esto, se suma el enjuiciamiento mediático del procesado.

Lastimosamente, en el Perú, mientras más mediático y comentado es un proceso penal, sea por el cargo del procesado o por su popularidad, más está sometido a la estigmatización por parte de los medios de comunicación. Los cuales, sin el más mínimo conocimiento jurídico, creen poseer la potestad propia de un juez para tildar de "delincuente" a un procesado o de "pruebas" a los más mínimos indicios. De nada sirve que el abogado defensor haga la mejor defensa de su vida, si el procesado ya fue enjuiciado por los medios de comunicación $\mathrm{y}$, consecuentemente, por la sociedad.

En este sentido, Beccaria (2020) afirmó que "ningún hombre puede ser llamado culpable antes de la sentencia del juez, ni la sociedad puede privarle de la protección pública, sino cuando se haya decidido que violó los actos en virtud de los cuales se le concedió esta"(43) (p .102).

Finalmente, cabe afirmar que, en el Perú, debería existir una regulación más estricta sobre estos supuestos. Pues, tanto los artículos 14 (derecho a la intimidad personal y familiar) y 15 (derecho a la imagen y a la voz) del Código Civil (1984), no protegen totalmente el derecho al honor ni tampoco a la presunción de inocencia. Debido a ello, es necesario disponer de una regulación similar a la que tienen otros territorios como Reino Unido, Italia y Australia, donde estos supuestos, lejos de ser enfrentados por la vía civil, también lo son por la vía penal ${ }^{(44)}$.

\subsection{Exceso de privaciones de libertad}

El mayor impedimento para una adecuada prevención especial se fundamenta en la privación de libertad. Según Roxin (2017), este tipo de pena está relacionada con efectos contrarios a la resocialización; entre estos sobresalen:

El aislamiento de la sociedad, que es nocivo para un entrenamiento de aprendizaje en lo social, la frecuente destrucción de vínculos humanos, sobre todo familiares, el fracaso profesional, el peligro de una infección criminal y la descalificación social ante los ojos de la opinión pública (p. 85).

Es deplorable que, en el Perú, a pesar de que, la reincorporación del penado a la sociedad se constituye como un objetivo constitucionalmente positivizado, se use excesivamente la privación de libertad. Incluso, llegando a ser el tipo de pena más aplicado por los jueces y, a su vez, el más nocivo y gravoso de todo el ordenamiento jurídico. Son alarmantes las cifras que el INPE (2020) puso a conocimiento público, puesto que reflejan el fracaso de la política criminal en la nación y, al mismo tiempo, dejan entrever la incongruente codificación realizada por el legislador. El siguiente gráfico presenta la cantidad de población penitenciaria del Perú, su distribución y el tipo de pena que cumplen.

Figura 5. Población total

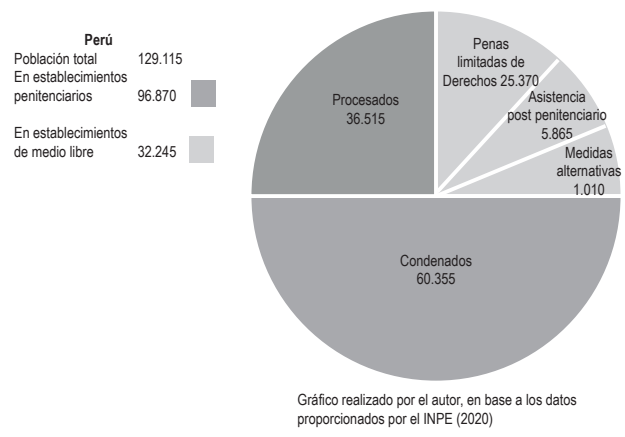

Fuente: Elaboración propia

(43) La cursiva es de Beccaria (2020).

(44) Siguiendo a Harbottle (2017), en Inglaterra el juez tiene la potestad de prohibir la mediatización de información del proceso; en Italia, debido a la existencia de la "ley mordaza", hay pena privativa de libertad y multas para quienes publiquen el contenido de actas y de escuchas telefónicas. Finalmente, en Australia por la vía penal son castigados los "juicios paralelos" que influyan abusivamente en un determinado proceso penal. 
Si se detalla la figura, el $75 \%$ de la población del sistema penitenciario se encuentra en un establecimiento (por prisión efectiva o prisión preventiva). Los individuos que afrontan este pesar varían entre condenados y procesados. Un caso completamente contrario es el que enfrenta Alemania, donde, según Roxin (2017), en 1990 se impusieron 83,3 \% multas y las penas privativas de libertad únicamente representaban el $5,3 \%$ de todas las penas impuestas.

Entonces, es adecuado preguntarse, ¿es acaso la solución de todo este embrollo optar por las otras penas privativas de derechos por sobre la pena privativa de libertad? Sin duda, la respuesta es negativa. Un ejemplo claro que permite hacer una idea es el de la suspensión de licencia para conducir, el cual fue proporcionado por Cury (2014). Esta pena pareciese adecuada cuando es aplicada al conductor de un camión que manejó en estado de ebriedad y causó un accidente. Pero carece de todo carácter poético, si la conducción de dicho camión era el único medio económico que el conductor tenía para alimentar a su familia. En este supuesto, es claro el carácter desocializador de dicha pena.

Sin embargo, Cury (2014) encuentra la solución cuando se plantea una pena en la que se reducen las consecuencias negativas "(...) otorgando al condenado autorización para continuar guiando su instrumento de trabajo únicamente en días y horas laborables" (p. 701). En este mismo sentido, ¿qué hay de las penas pecuniarias? Estas también generan un efecto desocializador en muchos casos. Un ejemplo claro podría ser el hurto de un reloj de alto precio realizado por una persona miserable, pobre y desesperada por sacar adelante a sus hijos. Si la pena hunde completamente en la miseria a su familia, esta persona se ve motivada a cometer nuevos delitos e incluso el efecto no termina en él, sino puede pesar sobre todos los miembros de su familia. Por ello, se puede llegar a la conclusión de que, mientras los jueces no tengan el tino para poder determinar cuándo se provoca un efecto adverso al perseguido, este tipo de penas producirá un efecto desocializador en gran parte de los casos.

\section{Epílogo}

Pareciera que en el Perú solo se busca la prevención general, pues existe un abismo de distancia entre la consolidación teórica y práctica respecto a la prevención especial. En países como Alemania sí se evidencia un gran avance y una concientización social sobre la finalidad de la pena lo que logra un cambio positivo. Sin embargo, Perú es "la otra cara de la moneda".

La comunidad carcelaria no solo deja entrever el fracaso del individuo perteneciente a ella, sino de todos los ciudadanos como sociedad y del país entero. Este no es un problema ajeno a los miembros de la sociedad, pues cada uno de los seres humanos están expuestos a pagar las consecuencias de la ineficacia del sistema penitenciario. Con esto no se quiere reafirmar la vieja creencia criminológica de que solo las personas marginadas por el Estado son quienes cometen delitos, dado que este punto de vista es actualmente insostenible, debido a la ya lejana aparición de los White Collar Crimes y del antes y después en la Política Criminal generado por Sutherland con su tesis American Sociological Review (1940).

El Perú es un país muy peculiar, puesto que se usa la tesis católica para abolir el aborto por sobre la tesis liberal o realista ${ }^{(45)}$. Cuando la positivización de esta primera se ve amenazada por algún proyecto ley o propuesta política, los grupos sociales y religiosos no tardan en movilizarse y protestar. Pero, si se habla de perdonar al delincuente o de "poner la otra mejilla", la percepción cambia abruptamente.

En general, existe un pensamiento derrotista sobre la inutilidad del sistema penitenciario con especial relieve en países tercermundistas como lo es el Perú. Mientras que mayor sea el análisis sobre la finalidad de la pena, más sentido y fuerza adquiere la tesis de Hullsman \& Bernat (1984)(46). Sin embargo, el jurista debe recordar aquellas bellas palabras escritas por Freire (1969) en su maravillosa obra Pedagogía del oprimido. La humanización es vocación negada, más afirmada también en la propia negación. "Vocación negada en la injusticia, en la

(45) El movimiento católico entiende que debe sancionarse el aborto en todas sus formas; este movimiento se encuentra positivizado en el Código Penal en el Capítulo Il del Título Primero. Asimismo, el movimiento liberal concibe que no debe sancionarse el aborto, dado que la mujer tiene derecho a decidir sobre su propio cuerpo. Finalmente, el movimiento realista se ampara en el respeto a la persona y su dignidad y, sobre todo, en aceptar que, en circunstancias previstas por la norma penal y practicadas debidamente, el aborto debe ser impune.

(46) Hulsman \& Bernat (1984) sostuvieron que, debido a la inutilidad por parte del sistema punitivo de poder brindar una prevención especial adecuada o al menos funcional, este sistema debería desaparecer totalmente. 
explotación, en la opresión, en la violencia de los opresores. Afirmada en el ansia de libertad, de justicia, de lucha de los oprimidos por la recuperación de su humanidad despojada" (p. 38).

\section{Conclusiones}

La teoría unificadora dialéctica, es acogida por el legislador peruano, debido a que presenta la mejor formulación teórica de entre todas las teorías. Asimismo, la gran cantidad de problemas que ostentan las teorías puras inducen al legislador a seguir legitimando el daño causado por la pena, mediante una teoría eclética.

En el marco normativo peruano, la pena asume diversos roles, dependiendo del estadio en el que opere. En la conminación asume una función preventivo general, en la aplicación, asume un rol preventivo general, preventivo especial y retributivo. Finalmente, en la ejecución penal, asume solamente un rol preventivo especial.

Pragmáticamente, el tipo de prevención que practica el Perú se fundamenta en la prevención general negativa con motivación en un deficiente proceso penal (prevención general inconsciente).

Los problemas que impiden la materialización de la prevención especial en la política criminal peruana son: la estigmatización, la presión mediática y el exceso de penas privativas de libertad.

Es necesaria la implementación de tipos penales que puedan reforzar la consistencia procesal, en los que se penalice la injerencia que tienen distintos medios de comunicación de forma desproporcionada, excesiva y mal intencionada dentro de los procesos penales.

Es sumamente necesario, priorizar una vía menos gravosa que la privación de libertad frente a la comisión delitos. Debido a que, la privación de libertad es completamente ineficiente cuando hablamos de resocialización.

Para poder combatir con la estigmatización del delincuente, es imperante la promoción de programas de concientización en la sociedad, esto mediante políticas públicas.

\section{Referencias bibliográficas}

Althaus, P. (1938). Adolf Schlatters Gabe an die systematische Theologie. Bertels-mann.

Althaus, P. (1955). Die Todesstrafe als Problem der christlichen Ethik. SAM.

Anderson, D. (2000). The Deterrence Hypothesis and Picking Pockets at the Pickpocket's Hanging. http://dx.doi.org/10.2139/ssrn.214831

Beccaria, C. (2020). De los delitos y las penas. Palestra Editores.
Becker, G. (1968). Crime and Punishment: An Economic Approach. Journal of political Economy, 76(2), 169-217.

Bentham, J. (1789). Una introducción a los principios de la moral y la legislación. Claridad.

Bentham, J. (1791). El panóptico. Alianza Editorial.

Bentham, J. (1830). The rationale of punishment. University of London.

Beytía, P. (2017). El panóptico de Bentham y la instrumentalización de los derechos humanos. Universitas Philosophica, 34(68), 173-196. https:// doi.org/10.11144/Javeriana.uph34-68.pbdh

Bonhoeffer, D. (2000). Ética. Trotta.

Borges, J. (2000). El Aleph. El Comercio.

Carnelluti, F. (2019). Lecciones sobre el proceso penal. Ediciones Jurídicas Olejnik.

Cury, E. (1988). La prevención especial como límite de la pena. Anuario de derecho penal y ciencias penales, 41(3), 685-702.

Custodio, G. (2016). Teorías absolutas de la pena. Ius Inkarri, 1. https://doi.org/10.31381/inkarri. v0i1.542.

Durán, M. (2011). Teorías absolutas de la pena: orígenes y fundamentos. Conceptos y críticas fundamentales a la teoría de la retribución moral de Immanuel Kant a propósito del neo-retribucionismo y del neo-proporcionalismo en el derecho penal actual. Revista de filosofía, 67, 123-144. http:// dx.doi.org/10.4067/S0718-43602011000100009

Feuerbach, A. (1989). Tratado de derecho penal. Editorial Ediar.

Freire, P. (1969). Pedagogía del oprimido. La Mano.

García, P. (2006). Acerca de la función de la pena. https://perso.unifr.ch/derechopenal/assets/files/ articulos/a_20080521_80.pdf

García, P. (2019) Derecho Penal. Parte General. Ideas Solución Editorial.

Gonzales, A. (s.f.). Teología del reino de Dios en el luteranismo político. Universidad Pontificia de Salamanca. https://summa.upsa.es/high. raw id $=0000007002$ \&name $=00000001$. original. pdf

Hansen, G. (2003). La crítica cristológica de Bonhoeffer a la hermenéutica "pseudoluterana" de las dos esferas. Numen: revista de estudos e perquisa de religiâo, 6(1), 31-78. https://periodicos. ufjf.br/index.php/numen/article/view/21653

Harbottle, F. (2017). Independencia Judicial y Juicios Penales Paralelos. ACADEMO Revista de Investigación en Ciencias Sociales y Humanidades, 4(1), 1. 
Hegel, F. (1821). Líneas fundamentales de la Filosofía del Derecho. s/e.

Hulsman, L., \& Bernat, J. (1984). Sistema penal y seguridad ciudadana. Hacia una alternativa. Ariel Derecho S.A.

Jakobs, G. (1991). Derecho Penal. Parte General. Trotta.

Jescheck, A., \& Weigend, T. (1996). Tratado de Derecho Penal. Parte General Volumen I. Instituto Pacifico.

Kant, I. (1785). La metafísica de las costumbres. Espasa-Calpe.

Klug, U. (1970). Para una crítica de la filosofía penal de Kant y Hegel. En M. Jiménez (ed.), Problemas actuales de las ciencias penales y la filosofía del Derecho. (pp. 35 y ss). Ediciones Pannedille.

Liszt, F. (1883). La idea de fin en Derecho penal. UNAM.

Lutero, M. (1580) Libro de la Concordia. s/e.

Luhmann, N. (1998). Complejidad y Modernidad: de la unidad a la diferencia. Trotta.
Meini, I. (2013). La pena: función y presupuestos. Derecho PUCP, 71, 141-167. https://doi.org/10.18800/derechopucp.201302.006

Mir Puig, S. (2016). Derecho Penal. Parte General. Reppertor.

Montesquieu. (1748). Del espíritu de las leyes. s/e.

Palma, R. (1872). Tradiciones peruanas. Editores Impacto Cultural S.A.C.

Pérez, C. (2013). Marcando al delincuente: estigmatización, castigo y cumplimiento del derecho. Revista Mexicana de Sociología, 75, 287-311.

Roxin, C. (1976). Sentido y límites de la pena estatal. Reus.

Roxin, C. (1994). Derecho Penal Parte General Tomo I. Civitas.

Roxin, C. (2017). La teoría del delito en la discusión actual Tomo I. Editora Jurídica Grijley.

San Martin, C. (2020). Derecho Procesal Penal Lecciones. INPECCP.

Silva, J. (2015). En busca del Derecho penal. Esbozos de una teoría realista del delito y de la pena. B de $\mathrm{F}$.

Taruffo, M., \& Nieva, J. (2013). Neurociencia y procesojudicial. Marcial Pons. Villavicencio, F. (2019). Derecho Penal. Parte General. Editora Jurídica Grijley.

Wessels, J., Beulke, W., \& Satzger, H. (2018). Derecho Penal. Parte General. Instituto Pacífico. 